Acceleration of Polarized Protons to Multi-GeV Energies and Experiments with Polarized Prolnns from 2-6 GoV/c

Invited Talk Presented at the Symposium on Iladron Physics at High Jincrgies Liblice, Czechoslovakia

June $16-21,1975$

L. G. Ratner

Argonae National Laboratory Argonne, Illinois 60437

This report was prepared as an account of work
sponsored by the United States Government. Neither
the United States nor the United States Energy
Research and Development Administration, ror any of
their cmployecs, nor any of their contractors,
subconiractors, or their employees, makes any
warranty, express or implied, or assumes any Icgal
linhility or responsibility for the accuracy, completeness
or usefulness of any informition. apparat us, froduct or
process disclosed, or represents that its use would not
infinge privately owned rights.

$\therefore$ Work supported by the U. S. Energy Research and Development
Administration 
I. Introduction

II. Acceleration of Polarized Protons

III. Experiments with Polarized Protons

A. Proton-Proton Total Cross Section

B. Two and Three Spin Measurements

1. Simultaneous measurement of 2 and 3 spin interactions

2. Measurement of $\mathrm{C}_{\mathrm{NN}}$ at 3,4,6 GeV/c

3. Measurement of $D_{N N}, D_{S S}$ and $H_{\text {ISSP }}$ at $6 \mathrm{GeV} / \mathrm{c}$

4. Micasurement of $D_{N N}$ at $6 \mathrm{GeV} / \mathrm{c}$

C. Pclariation Measurements in Nucleon-Nucleon Elastic Scattering

1. Small angle polarization in elastic P-Pscattering

2. Neutron-Proton and Proton-Proton Polarization at 2,3 , $4,6 \mathrm{GeV} / \mathrm{c}$

D. Inelastic Interactions

1. $N$ and $\triangle$ Production in the Effective Mass Spectrometer

E. Inclusive $\wedge$ Production

1. Effective Mass Spectrometer Experiment

2. Exposure in the $12 \mathrm{ft}$ Hydrogen Bubble Chamber

F. Coherent Folarized Prolon ${ }^{4}$ He Interactions

G. Parity Tests. 
Acceleration of Polarized Proluns to Multi-Civi Enorgics and

Experiments with Folarized Protons from $2-6 \mathrm{C} \cdot \mathrm{V} / \mathrm{C}$

I. Introduction

In July 1973 polarized protons were successfully accelerated to $6 \mathrm{GeV} / \mathrm{c}$ in the Zero Gradient Synchrotron (ZCS) at the Argonne National Laboratory. (1) Since then, there have been 26 wecks of accelerator operation with polarized protons for both experimental physics and machine improvements. Accelerated intensity has increased from $10^{8}$ polarized protons per pulse (pppp) to $6 \times 10^{9}$ pppp during this time. The polarization of the extracted beam is $73 \% \pm 8 \%$ for an injected beam polarization of $73 \% \pm 6 \%$. Luring machine studies, polarized beam has been accelerated to $8.5 \mathrm{GeV} / \mathrm{c}$ and it is felt that there are no technical problems in accelerating to $12.0 \mathrm{GeV} / \mathrm{c}$, which is presently scheduled for spring 1976. Some 12 experiments ${ }^{(2)}$ have taken data during this period and $\bar{l}$ will present most of the results to date. The layout of the experimental area is shown in figure l. Four to five experiments have been able to take data simultaneously during most of the operating period.

The periection of polarized target techniques and the operation of a high energy polarized beam makes accessi ble a rich new field of physics. Experiments which seemed almost impossible a few years ago are now being planned and done. It appears that within the next few years we will have a complete set of amplitudes for the P-P system in the few GeV energy range. This could lead to a much better understanding of one of the most fundamental problems of high energy physics, namely the P-P interaction.

Another puzzling feature of the P-P interaction. is the breaks observed in the fixed angle cross section. As we will see later these also exisc in the pure spin state cross sections and polarized beam polarized target experiments may lead to urierstanding this phenomenon. In addition, once the helicity amplitudes are known, parton type models can be put to rather stringent tests. It appears that the experiments 
which are now underway will adel a gocd deal of knowledge not only to the P-P interaction but to all of hadron physics.

\section{Accelerator Operation}

Protons are initially polarized in a ground state atomic beam source and emerge at $20 \mathrm{keV}$. They are then accelerated to $750 \mathrm{keV}$ in a Cockeroft-Walton and then to $50 \mathrm{MeV}$ in a linear accelerator. They are then injected into the synchrotron and accelerated to GeV energies. The major problem in accelerating polarized protons is the depolarization which can occur during the acceleration process.

When particles with a vertical polarization are injected into a synchrotron with a vertical guicle field, the spin of the particles will precess about the vertical axis. Lepolarization is caused by any horizontal field components that may be present. Since the ZGS is a weak focusing accelerator, it has no strong focusing quadrupoles with horizontal field components. Moreover, the field uniformity inside the 8 octant magnets is excellent, so they have no significant horizontal fields. The only significant horizontal ficlds are the fringe fields at the 16 -edges of the octants and the se can cause depolarization.

One can lefine two types of depolarization: nonresonant and resonant. Nonresonant depolarization occurs when a polarized particle sees a random horizontal field component once during the acceleration cycle and then never again. Fields too small to drive the beam vertically out of the ZGS will give a very small nonresonant depolarization. For each pass through a ZGS octant fringe field, the depolarization is estiI jated to be less than $10^{-9}$.

Resonant depolarization occurs when particles circling a synchrotron sce a similar horiznntal field on many successive turns. This can be much more serious, since the depolarizing amplitudes from each turn can add coherently and quickly destroy the polarization. One type of depolarizing resonance comes from imperfections in the magnets. For the ZGS these are quite small but can be significant for some synchrotrons. (3) There are also "intrinsic" depolarizing resonances 
which occur when the protons sca periodically oscillating horizontal fields due to their vertical betatron oscillations. This vertical motion makes the protons periodically pass through the octant fringe fields at a vertical position where there is a significant horizontal field. When the frequency for passing through such a field becomes equal to the spin precessional frequency, the spin gets a similar depolarizing anılitude for many passes and there is a large depolarization.

For the ZGS these "intrinsic" depolarizing resonances can be quite serious. They occur at several values of $Y$ during the acceleration cycle and if no corrective action is taken they will destroy most of the polarization before $5 \mathrm{GeV} / \mathrm{c}$ is reached.

In the ZGS there are 10 depolarizing resonances between injection and 12.0 GeV/c. Four of the se arevery strong and six are weak. To reduce the effect of these resonances, one can shift the vertical tune of the machine very rapidly just at the resonance. This is accomplished by using a pair of pulsed quadrupoles which operate at $2500 \mathrm{G}-\mathrm{in} / \mathrm{in}$ with a $20 \mu \mathrm{sec}$ rise time. The effect of the quadrupoles is shown in Figure 2 .

\section{Experiments}

A.

\section{Total Cross Section Experiment}

The $\sigma_{\text {TOT }}$ measurement was a standard "good geometry" attenuation experiment whose layout is shown in figure 3 . The polarized beam from the ZGS first passes through a $\mathrm{H}_{2}$ target. The left-right asymmetry from the elastic scattering is measured by the four-arm spectrometer. Left scattering for the forward particle in $L 1,2,3$ and the left recoil particle in L4, 5 and 6 . Right scattering is similarly measured in R1, 2, 3 and $R 4$, 5 and 6 . This measurement gives the beam polarization which was $70 \%$. The beam continues downstream to a series of counters and the polarized target (PPT). This target was $86 \%$ polarized. The incident beam of $2 \cdot 10^{5}$ pppp was counted by the I counters 
with an anticoincidence $A$ counter to reduce accidentals. The A counter had a $3 / 4$ in. diameter hole to allow the beam through. The attenuated beam after the PPT was counted by $O$ counters which were respectively $10,9,6,4$ and 2 in. in diameter. At $6 \mathrm{GeV} / \mathrm{c}, 3 \times 10^{10}$ events were accumulated. The beam polarization. was flipped on a pulse-to-pulse basis and the target polarization about twice a day to remove systematic errors. The quantity measured was the difference $\Delta \sigma_{\text {TOT }}=\sigma_{\text {TOT }}(\uparrow \downarrow)-\sigma_{\text {TOT }}\{\uparrow)$, which is the difference in the total cross section for beam polarization up target polarization down and both beam and target polarization up. The se are, of course, equivalent to the spin flipped condition by rotational invariance of space which insures that

$$
\begin{aligned}
& \sigma_{\text {TOT }}(\uparrow \uparrow)=\sigma_{\operatorname{TOT}}(\downarrow \downarrow) \text { and } \sigma_{\text {TOT }}(\downarrow \uparrow)=\sigma_{\text {TOT }}(\uparrow \downarrow) \\
& \Delta \sigma_{\text {TOT }}=-\frac{[I(\mathrm{O}) / \mathrm{I}] \uparrow \downarrow-[\mathrm{I}(\mathrm{O}) / \mathrm{I}] \uparrow \uparrow}{\left[\mathrm{I}(\mathrm{O}) / \mathrm{I}>\mathrm{N}_{\mathrm{O}} \rho \mathrm{t} \mathrm{P}_{\mathrm{B}} \mathrm{P}_{\mathrm{T}}\right.}
\end{aligned}
$$

where the numerator contains the ratios of the transmitted event coincidences $I(O)$ to the number of protons $I$ for the two different spin states which are perpendicular to the beam direction. $<\mathrm{I}(\mathrm{O}) / \mathrm{I}>$ is the spin average value of this ratio. $\mathrm{N}_{0}$ is Avagadros number $6.02 \times 10^{23}$ while $\rho=0.073 \pm 0.005$ is the density of hydrogen protons in the polarized target and $t=4.13 \mathrm{~cm}$ is the length of the polarized proton target. $P_{B}$ and $P_{T}$ are the beam and target polarization which were $(70 \pm 5) \%_{0}$ and $(86 \pm 5) \%$.

The measured total cross-sections are clearly nonzero and positive. The anti-parallel cross-section $\sigma_{\text {TOT }}(\uparrow \downarrow)$ 
larger than the parallel cross section $v_{\text {IOT }}(\uparrow \uparrow)$. There is also a very large value of $\Delta \sigma$ TOT of ilmost $6 \mathrm{mb}$ at 2 GeV/c compared to the $0.76 \mathrm{mb}$ at $3 \mathrm{GeV} / \mathrm{c}$.

B. Two and three spin proton clastic scattering measurements

1. The configuration of the preceding experiment was modified by adding a spactrometer after the polarized target and by remoing the total cross-section counters. This is shown in figlure 4. The elastic cross-section for the scattering of the polarized proton beam on the polarized proton target was measured using this two arin spectrometer containing magnets and scintillation counters (FIF2F3 Bl B2B3). The incident $6 \mathrm{GeV} / \mathrm{c}$ beam contained about $3 \times 10^{8}$ polarized protons with a beam polarization oi $69 \pm 4 \%$. The pola rized target was $75 \pm 5 \%$. The relaive cross sectirn for the four differcnt initial spin states $\uparrow \uparrow, \downarrow \downarrow, \uparrow \downarrow, \downarrow \uparrow \quad$ was measured. Since both the beam and target were only partially polarized $\left(\mathrm{P}_{\mathrm{B}}\right.$ and $\mathrm{P}_{\mathrm{T}}$ ) the rclative cross sections were obtained from the equations shown in figure 4. $\langle\mathrm{d} \sigma / d \Omega>$ is the spin average crosssection and the $N_{i j}$ is the normalized event rates in each state. The as ymmetry parameter $A$ is obtained by averaging over either the beam or target polarization. This gave a consistency check which typically held to within $\pm 1 \%$. The values of $A$ and $C_{N N}$ are plotted agrainst $P_{\perp}^{2}$, in figure 5 . $\mathrm{C}_{\mathrm{NN}}$ has a maximum around $\mathrm{P}_{\perp}^{2}=0.7(\mathrm{GeV} / \mathrm{c})^{2}$ which is where $A$ has a minimum and is about where there is a break in the spin average cross section.

Next we turn to the measurement of the recoil proton spin using the B-polarimeter shown in figure 4 . This observes the scattering of the $225 \pm 30 \mathrm{MeV}$ recoil proton at $\mathrm{P}_{\perp}^{2}=0.5$ 
(Geyte $)^{2}$ from a 5 in. long earbon block. Measuring the isymmetry in p-C relastic scattering to the left and to the right we obtain the recoil polarizarion. We estimated the effective analyzing nower to be $\mathrm{A}_{\mathrm{pC}}=0.50 \pm 0.05$ using the data of Chamberlain et al. at $284 \mathrm{MeV}$.

Thus for each uf the 4 initial spin states $(\uparrow \uparrow, \downarrow \downarrow \uparrow !$ and $i$ we measure $P_{R}$ and thus obtain the number of recoil protons in each state. Folding in the partial polarization of the heam and target $\left(P_{B}\right.$ and $\left.P_{T}\right)$ we then obtain the cross-sections for the b different spin states:

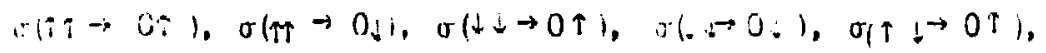

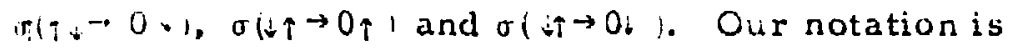
o(biam, target $\rightarrow$ scattered, recoil) and 0 denotes unmeasured. If we assume parity irviriance thron all 8 single flip amplitudes nust be zero (e.g., $\sigma(\uparrow \uparrow \rightarrow i \uparrow)=0$ ). Then the 8 cross sertions above are in fact the 8 pure spin state cross-sections: $\sigma\left(\uparrow \uparrow \rightarrow \uparrow \uparrow \uparrow, \forall \uparrow \uparrow_{\uparrow} \rightarrow \downarrow, \sigma \biguplus \rightarrow \rightarrow \uparrow \uparrow\right.$,

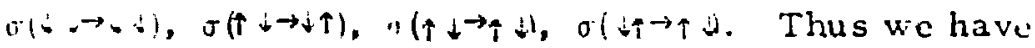
measured directly the square of the magnitude of the amolitudes for the 8 pure transversity states but have no information about their phases. Rotational invariance of space gives two relations between these

$$
\begin{aligned}
& \sigma(\uparrow \leftrightarrow \uparrow \downarrow)=\sigma(\downarrow \uparrow \rightarrow \downarrow) \text { antiparallel non flip } \\
& \sigma(\uparrow \downarrow \downarrow \uparrow)=\sigma(\downarrow \uparrow \rightarrow \uparrow \downarrow) \text { antiparallel double flip }
\end{aligned}
$$

and $\mathrm{T}$ invariance give another

$$
\sigma(\uparrow \uparrow \downarrow \downarrow)=\sigma(\downarrow \downarrow \uparrow \uparrow) \text { parallel double flip }
$$


by asstaming that 1 and $T$ invariance hold ond cin ale?the the cross-section: iven above lo obt.tin the alt $\rightarrow+t)$,

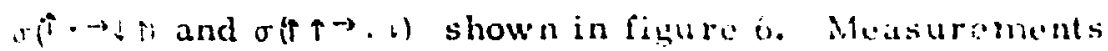
$0:$ the other two of the 5 incependent tranversity cross scetions $\sigma(\uparrow \uparrow \rightarrow \uparrow \uparrow)$ and of $(\downarrow \downarrow \rightarrow \downarrow)$ are also shown.

Fo: the antiparallel non flip there is suffeient presision tor a fair test of $P$ invariance. One finds

$$
\frac{a(\uparrow \rightarrow 0+1-.1+\uparrow \rightarrow 0 \uparrow)}{v(\uparrow+0 !)-1(2 \uparrow+0 \uparrow)}=-0.02 \pm 0.05 .
$$

This sots an upper limit on the single lip cross sections

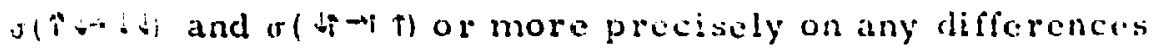
between these two $"$-violating cross sections. The other wo tests involve smaller double ilip amplitudes for which the precision is inielequate.

The most interesting feature sun in figur. 6 is that the doubie fipp cross sections ar"e typically 10 times smaller

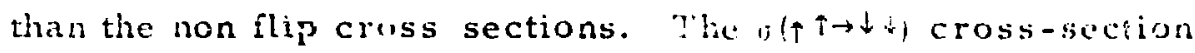

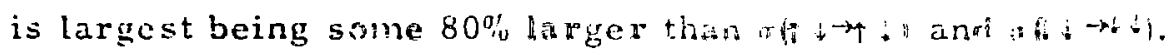
Another way to preant this cata is in troms at the Wolfonstrio parameters $D_{n n}$ anrl $K_{n a}$. We find that $D_{n n}=0.81 \pm 0.10$, $n_{n n}=0.14=0.08$.

Finally in figure 7 is plotted the dificrential elastic cross sections themselves against $\mathrm{p}_{-}^{2}$ rather than the cross section ratios. This more cluarly demonstrates the relationship betwern the change in the spin dependence and the break in the cross section.

In the "diffraction peak" region of $P^{2}<1(\mathrm{GeV} / \mathrm{c})^{2}$ the three cross sections are parallel and $\sigma(\uparrow \uparrow)$ is about $40 \%$ larger than $\sigma(\downarrow \downarrow)$ and $\sigma(\uparrow \mid)$ which are about equal. In the second region after the break $\left[\mathrm{P}_{1}^{2}>1(\mathrm{GeV} / \mathrm{c})^{2}\right]$ cross-scctions are also parallel to each other but $\sigma(\uparrow \uparrow)$ is now about twice as big as $\sigma(\downarrow \downarrow)$; and $\sigma(\uparrow \downarrow)$ is about haif-way between them. 
The shurp broaks and the two cases of rather different Lut jarallel behavior are quite striking. Further work will be cone to meatiure the 2 and 3 spin cross-sections as a function of $\mathrm{P}_{+}^{2}$.

\section{GN Mirasurements}

Measurements have been made at $2,3,4,6 \mathrm{GeV} / \mathrm{c}$ wer $a(-t)$ range of 0.08 to 1.4 at $u \mathrm{GoV} / \mathrm{c}$ and 0.1 to 2.5 iti 3 Cielic. The dita at 2 and 4 Gelic is very similar to i Ciel / when plottorl against 0 . The analysis of the 2 , $+\mathrm{CeV} / \mathrm{c}$ is very proliminary. The data at $6 \mathrm{GeV} / \mathrm{c}$ represents ibout $1 / 5$ of the total events and the data at $3 \mathrm{GeV} / \mathrm{c}$ is also preliminary. The yroup involved in this experiment is beginning a program to measure anough quantities of the type ciefined by Wolfenstein and Ashkin to be able to give a tnique reconstruction of the nucleon-nucleon scattering dita. Besides the C ${ }_{N N}$ data, they have collected some data using a spin rotating solenoid and recoil polarimeter. Their measurements are of $(S, O ; O, S),(S, N ; O, S),(O, N ; O, N)$ where the quantities in parenthesis represent (beam, target; scattered, recoil) spin. $S$ is the polarization state transverse to the momentum in the scattering plane and $\mathrm{N}$ is the polarization state normal to the scattering plane. $O$ is an unmeasured polarization slate. Analysis of this data has just started. This group is also building $a$ " $R$ " and " $A$ " magnet for the polarized target which will allow $P_{T}=\left\{S\right.$ and $\left.I_{\text {.. }}\right\}$ where $L$ is the polarization state along the particle momentum in the laboratory frame. 
For the $C_{\text {NN }}$ measurements shown in figures and 4 , data were then for the four possible combirations of up and down oriontation of the beam and target polariadiuns. The polariced target wis suryounded by proportional wire chamber hodoscopes atal iree proton events were separated from bound proton arents by means of the angular correlation. The rates at a given angle ran be expressed as

$$
I(t)=I_{0}(t) i_{1} \cdot\left[\left( \pm P_{B}\right)+i \pm P_{I}{ }^{\prime} A \div\left( \pm P_{B B}\right)\left( \pm P_{T}\right) C_{N N} .\right.
$$

As can be seen in figure 8 here is a strong rnergy indopendence between the low energy data and the 6.0 CieV/c data, In figure 9, one can see a rise with increasing t. This however is still very preliminary. There appears to be some problem as evidenced by the non-symmetry about $90^{\circ} \mathrm{cm}$.

\section{3. $\underline{\mathrm{DNN}}_{\mathrm{Ne}}$ Measurements}

This experiment was done with an unpolarized beam on a polarized target and used a carbon analyzer for the recoil particle. It thus studies the change in the polarization of the initial state proton as a result of the scattering process and measured the wolfenstein $\mathrm{D}$ parameter. The results are shown in figure 10. The princiral feature to be not:ced is that at small $t, D$ is close to 1 . Thus the spin of the polarized target proton is not appreciably changed by the 


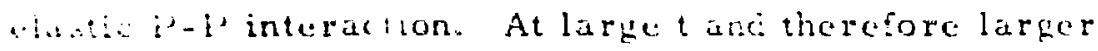
industun transfer D secms to doviate from 1.

Lefore we leare the subject of these correlation

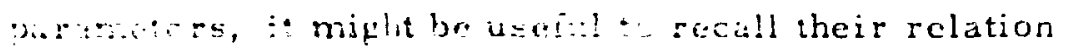
tw the scitering motrix. Using the notation of

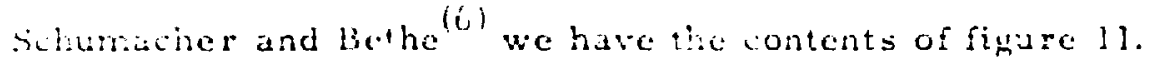
$\therefore_{7}$ i. the scatterin matrix: $\sigma_{1},{ }_{2}$ inc pauli matrices are the coordinate system is definerl by $\mathrm{m}, \mathrm{p}$, q vectors.

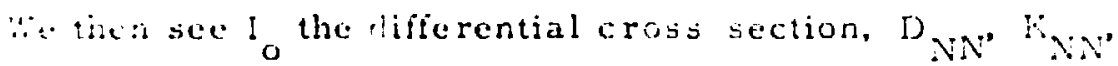
arre 6 in terms of the coeticients withe scattering natrix The last quantities are $\vdots_{0}$ "were is is the polariadion. This is the next set of experinents to be presented.

C. Polariation Mrasurenients in PP Flastic scattering

1. Sinall angle proton-proton elastic scattering, fintre 12 , flows the results of the measurcuints of the polarization patacier in small angle proton-protun clastic scattering ai $i$ coric. The pularization rise like -1 in the interval $0.12 \cdots-t<0.1(G a \because)^{2}$. The se misuraments were done with pelarized bean and used the Eitective Mass Spectromeder. Facility which will be described later. The beam was incident on a $50 \mathrm{~cm}$ liquid hydrogen target. The forward scattered pariicles were neasured in five sets of magnetustrictive wire spark chambers placed before, within, and behind a iarge aperture magnet. The mean resolution in $-t$, was $\pm 0.006(\mathrm{GeV})^{2}$. Ihese results combined with those of Borghini et al. ${ }^{(7)}$ are well fit by the compirical formula

$$
P(t)=(0.506 \pm 0.021) \sqrt{-t} \exp -(2.52 \pm 0.18) t]
$$


over the interval $-t=0.02$ to $0.5(\mathrm{GeV})^{2}$. Using the notation $0:$ Halzen and Thomas ${ }^{(8)}$ for $t$ channel exchange we have

$$
\begin{aligned}
& \frac{\mathrm{d} \sigma}{\mathrm{dt}}=\left|\mathrm{N}_{0}\right|^{2}+2\left|\mathrm{~N}_{1}\right|^{2}+\left|\mathrm{N}_{2}\right|^{2}+|\mathrm{A}|^{2}+|\pi|^{2} \\
& P \frac{\mathrm{d} \sigma}{\mathrm{dt}}=2 \mathrm{I}_{\mathrm{m}}\left(\mathrm{N}_{0}-\mathrm{N}_{2}\right) * \mathrm{~N}_{1}
\end{aligned}
$$

The polarization here depends only on the amplitudes $N_{0}, N_{1}$ and $N_{2}$, all with natural-parity exchange in the $t$ channel; it does not depend on $\pi$ and $A$, the unnaturalparity exchange amplitudes corresponding to $\pi$ and $\mathrm{A}_{1}$ quantum number exchange. The non-flip amplitude $\mathrm{N}_{\mathrm{O}}$ has a large diffractive comfonent and is the dominant amplitude near the forward direction. Using results from a previous experiment with the same apparatus, (9)

$$
N_{0} \approx \sqrt{d \sigma / d t}=9 e^{3.8 t}\left(\mathrm{mb}^{3} \mathrm{GeV}^{2}\right)^{1 / 2}
$$

Ignoring the double flip amplitude $\mathrm{N}_{2}$, one can use the polarization to estimate the component of the single-flip amplitude orthogonal to $N_{0}$ in the complex plane,

$$
N_{i \perp} \approx 1 / 2 \mathrm{P} \cdot \overline{\mathrm{d} \sigma / \mathrm{dt}}=2.3 \sqrt{-\mathrm{t}} \mathrm{e}^{6.3 \mathrm{t}}\left(\mathrm{mb} / \mathrm{GeV}^{2}\right)^{1 / 2}
$$

The ratio of amplitudes $\mathrm{N}_{1 \perp} /\left|\mathrm{N}_{0}\right| \approx \mathrm{P} / 2$, is approximately $6 \%$ over the region $-\mathrm{t}=0.06$ to $8.5(\mathrm{GeV})^{2}$. 


\section{Comparison of PP and PN Polarization}

This experiment was also done in the Effective Mass Spectrometer which consists basically of a large aperture magnet with spark chambers. The facility is very flexible and one can form triggers for many reactions. Figure 13 shows a sketch of the facility and alsc lists the data accumulated to date in polarized beam running. Over five million events have been collected and a great deal of this has been analyzed. I will only be able to cover a small portion of the available data today.

Figure 14 shows the results of the polarization measurements in $P P$ and $P N$ scattering at 2 and $6 \mathrm{GeV} / \mathrm{c}$. The data at 3 and $4 \mathrm{GeV} / \mathrm{c}$ lie in between with 4 looking more like 6 and 3 more like $2 \mathrm{GeV} / \mathrm{c}$. It is obvious that the NP system is not mirror symmetric like the $\pi^{+} \pi^{-}$ system. In the $t$ channel exchange language, the flip amplitude is mainly $I_{t}=0$ or no $p, A_{2}$ exchange at 2 and $3 \mathrm{GeV} / \mathrm{c}$. The $I_{t}=1$ part falls more slowly with energy and becomes equal to $I_{t}=0$ at $6 \mathrm{GeV} / \mathrm{c}$ depending on $t$. We also can see a dramatic change at $-t=0.3 \mathrm{GeV}^{2}$ in the ratio of $\mathrm{PP}$ PN polarization. The ratio is 0.8 at $2 \mathrm{GeV} / \mathrm{c}$ and 0.2 at $6 \mathrm{GeV} / \mathrm{c}$. This was not anticipated by any model. Using the HalzenThomas notation again; the $R e N_{1}$ is measured by the polarization. $\mathrm{N}_{1}$ can be broken up into a part corresponding to $I=0$ exchange in the $t$ channel ( $\omega, f$, Pomeron), and an $I=1$ part $\left(\rho, A_{2}\right)$. If we compare the 2 and $6 \mathrm{GeV} / \mathrm{c}$ data, we find a large change in the ratio of the $\operatorname{Re} N_{1}(I=0)$ to $\operatorname{Re} N_{1}(I=1)$. This ratio changes by almost an order of magnitude. Figure 15 is a plot of the single-flip natural parity exchange amplitudes 
and figure 16 is a power law fit to the ingle flip amplitude. We see that

$$
\begin{aligned}
& a_{I-0}=-0.6+0.6 t \\
& a_{I-I}=+0.1-0.1 \mathrm{t}
\end{aligned}
$$

\section{Inclastic Interactions}

\section{1. $N^{*}$ and $\Delta$ Production}

The EMS looks at the decay products of fast forward $\mathrm{N}^{*}$ 'S that are associated with the poiarized beam proton. The prescnt experiment uses the transversely polarized beam but longitudinal pola rization experiments are also technically feasible and useful. For the present experiments the EMS was triggered on multi-particle events ( $\geq 2$ forward tracks). To monitor the incident beam polarization elastic scatters we re simultaneously recorded. A large aperture hodoscopic Cerenkov counter was used to differentiate fast pions and protons. With $6 \mathrm{GeV}^{\prime} \mathrm{c}$ beam momentum, the geometric acceptance for a typical reaction, $\mathrm{Pt} \mathrm{P} \rightarrow\left(\mathrm{P}^{+}\right) \mathrm{n}$ is $\sim 400^{\prime}$. Figure 17 shows events as a function of $\mathrm{P}_{\pi^{-}}$mass and the surprisingly large polarization in thr. $\Delta^{++}$production.

Figure 18 shows the number of events in $\mathrm{P} \uparrow \mathrm{P} \rightarrow \mathrm{P}_{\pi}^{-} \mathrm{P}$. and Figure 19 the evants in $\mathrm{P} \uparrow \mathrm{P} \rightarrow \mathrm{P}^{+} \mathrm{N}$.

Figure 20 compares the natural and unnatural parity cross section for the $\Delta^{++}$and $K^{\circ * k}(890)$.

The quark model predicts that the natural parity cross section for $\Delta^{++}$and $K^{* 0}(890)$ should be equal. 
They do have the same $t$ dependance and it is different then ror the $\overline{\mathrm{K}}^{\circ *}$ (890).

One can study the spin-parity content of the $\mathrm{P}_{\pi}{ }^{+}{ }_{\pi}{ }^{-}$ system with the reactions $\mathrm{P} \uparrow \mathrm{P} \rightarrow \mathrm{P}_{\pi}{ }^{+}{ }_{\pi}{ }^{-} \mathrm{P}$

$$
\begin{aligned}
& \mathrm{P} \uparrow \rightarrow \mathrm{P}^{+}{ }^{+}-N \\
& \mathrm{P} \uparrow \mathrm{d} \rightarrow \mathrm{P}^{+}{ }^{+}-\mathrm{d}
\end{aligned}
$$

Figure 21 shows some data for $\mathrm{P}_{\uparrow} \mathrm{P} \rightarrow \mathrm{P}_{\pi}{ }^{+} \pi{ }^{-} \mathrm{P}$ and one observes small peaks at masses of 1400,1500, 1660 MoV. The 1400 peak is seen only at very small t.

\section{E. Inclusive A Production}

\section{Effective mass spectrometer experiment}

This experiment was done in the EMS and now has over $10^{4}$ analyzed events with less than $2 \%$ background. The results are best discussed in terms of a straightforward generalization of the Wolfenstein parameters shown in Figure 22.

$$
\begin{aligned}
& \sigma=\sigma_{0}\left[1+\left(\mathrm{P}-\mathrm{P}^{\prime}\right) \overline{\mathrm{e}} \cdot \hat{\mathrm{n}}\right] \\
& \sigma \overline{\mathrm{f}} \cdot \hat{\mathrm{n}}=\sigma_{\mathrm{o}}\left[\left(\mathrm{P}+\mathrm{P}^{\prime}\right)+\mathrm{D} \overline{\mathrm{e}} \cdot \hat{\mathrm{n}}\right]
\end{aligned}
$$

where

$\bar{e}$ is the beam polarization and $\bar{f}$ is the $\wedge^{\circ}$ Folarization, and $\hat{n}$ is the production plane unit normial.

$\left(P-P^{\prime}\right)$ is the analyzing power or scattering asymmetry of the production process and $\left(P+P^{\prime}\right)$ is the polarization or polarizing power. These two are equal by time reversal in elastic processes, but do not have to be equal in inelastic 
processes. The "clepolarization" parameter D has the same meaning as in elastic scattering.

These parameters were looked at as a function of the Feynman scaling variable $x$. For $x>0.75$ inequality of polarization and analyzing power as shown in figure 23. The natural parity exchange expectation that $D=I$ near $x=1$ is not borne out by the data as shown in algure 24. The diata look nothing like R. D. Field's triple - Ragge ${ }^{(10)}$ results. The value of $D \sim-0.4$ near $\mathrm{x}=1 \mathrm{might}$ be due $\mathrm{w} \wedge^{\circ} \mathrm{S}$ from the decay of low-spin diffractively produced $\mathrm{N}^{* \prime} \mathrm{S}$.

\section{2. $12 \mathrm{ft}$ Bubble Chamber Exposure}

W. J. Fickinger and D. K. Robinson of Case Western Reserve Univerisity and A. Engler and R. W. Kraemer have an exposure of 150,000 pictures with $6 \mathrm{GeV} / \mathrm{c}$ polarized protons. These have been scanned for V's. They have looked at $\wedge$ and $K$ production and have a very preliminary indication, based on 260 events, that there seems to be a $60 \%$ asymmetry in $\mathrm{K}^{\circ}$ production at a 4 standard deviation level. $\wedge$ production seem to show no asymmetry.

F. Coherent Polarized Proton ${ }^{4}$ He Interactions

This experiment has harl a test run of 49,000 pictures at $6 \mathrm{GeV} / \mathrm{c}$ and the film is now being scanned to evaluate the effectiveness of the trigger and the number of pictures necessary for a good experiment. The experiment is planned for $\sim 9 \mathrm{GeV} / \mathrm{c}$. The 1. $5 \mathrm{METER}$ streamer chamber is filled with helium at one atmosphere. The 
chamber gas is both target and detector. The trigger is simply an incoming proton, no outgoing beam, and a multiplicity $\geq 2$ in a multi-wire proportional counter at the downstream end of the chamber. The recoil range and momentum is measured in the chamber gas. This is show'r schematically in figure 25.

\section{G. Parity Tests}

The group involved in this experiment has previously pubLished a result of $(1 \pm 4) \times 10^{-7}$ for the parity-nonconserving component in proton-proton scattering at $15 \mathrm{MeV}$. (1) A simular experiment is being done at the ZGS at $6 \mathrm{GeV} / \mathrm{c}$ in p-nucleus interaction in order to obtain informationon the energy dependence of the effect. The apparatus is shown in figure 26. The polarized beam was used to measure the dependence of the P-Be total-scattering cross section on the psendoscalar quantity $\vec{S} \cdot \vec{P}$, where $\vec{S}$ is the spin of the incident proton and $\vec{P}$ its momentum. If parity is conserved in the interaction between nucleons, the cross section is independent of $\vec{S} \cdot \vec{P}$. Effects are expected to be of the order of $10^{-5}$ to $10^{-7}$. Integral counting techniques were used with two independent systems, one consisting of ionization chambers and the other photomultipliers coupled to scintillators. The target was $20 \mathrm{~cm}$ of Be. The bending magnet has a horizontal field and bends the protons down by $7.75^{\circ}$ which rotates the spin so that it is aligned with the momentum. In thei $i$ first run they obtained $(-1.4 \pm 2.6) \times 10^{-5}$ from the ion chambers and $(5 \pm 9) \times 10^{-6}$ from the scintillator system. In a run recently completed, new detectors were added to the system. These gave signals related to position and angle of the beam, beam spot size, and residual transverse polarization. Ion chambers and scintillator data were recorded on the same computer so that beam property corrections could more easily be made to both. The 
results are still being analysed but a preliminary value should be announced shortly.

\section{Acknowledgements}

I would like to thank the authors of all the experiments I have mentioned for their information, both published and unpublished.

\section{$\underline{\text { Reierences }}$}

1. T. Khoe et. al. Acceleration of Polarized Protons tu $8.5 \mathrm{GeV} / \mathrm{c}$. To be published in Particle Accelerators.

2. The following experiments and their ZGS number have taken data with the polarized beam. The experiment spokesman is listed as a source of further information.

E-324 Total Proton-Proton Cross Sections Using a Polarized

Target and a Polarized Beam - A. D. Krisch, University of Michigan.

E-336 Measurement of $\wedge^{\prime} s$ Produced by a Polarized Proton

Beam - R. Winston, University of Chicago,

E-339 Study of Resonance Production with a Polariced Proton Beam Using the Effective Mass Spectrometer -

A. B. Wicklund, Arganne National Laboratory. Study of Coherent Polarized Proton ${ }^{4} \mathrm{He}$ Interactions A. Fridman, Institut de Physique Nucleaire de Strasbourg. E-354 Parity Violation in Proton Scattering Processes D. E. Nagle, Los Alamos Scientific Laboratory. E-364 Mcasurement of the Polarization Parameter of Small Angles in PP Flastic Scattering - D. R. Rust, University of Indiana.

E-366 Measurement of the Recoil Spin in PP Elastic Scattering with a Polarized Beam and Polarized Target - 
A. D. Krisch, University of Michigan.

$E-367$

Study of 6 and $12 \mathrm{GeV} / \mathrm{c}$ PP Interactions Using the ZGS Polarized Beam and the $12 \mathrm{ft}$ Chamber -

D. K. Robinson, Case Western Reserve University.

$E-372$

Proton-Proton Elastic Scattering with Polarized

Proton Beams and Determination of P-P Scattering

Amplitudes - 1). Miller, Northwestern University.

E- 370

Measurement of the Folarization Parameter for PN

Elastic Scattering from 2 to $6 \mathrm{GeV} / \mathrm{C}-\mathrm{R}$. E. Dicbold, Argonne National Laboratory.

$E-381$

Elastic PP Cross Sections Using a Polarized Target and a Polarized Beam - A. D. Krisch, University of Michigan.

$E-385$

Proton-Proton Scattering with S-Type Polarized Proton Beams, N-Type Polarized Target and a Spin Analyzer for liecoil Protons - B. Sandler, Argonne National Laboratory.

3. D. Mohl Possibility of Acceleration of Polarized Protons in the CERN-PS Proceedings of the Summer Studies on High-Energy Physics with Polarized Beams. ANL/HEP 75-1)2(1974).

4. O. Chamberlain et. al., Phys. Rev. 102, $11950 ! 1659$.

5. L. Wolfenstein and J. Ashkin, Phys. Rev. 155 (1952) 947; L. Wolfenstein, Phys. Rev. $96(1954) 1654$

6. C. R. Schumacher and H. A. Bethe, Phys. Rev. 121 (1961) 1534.

7. M. Borghini, et. al., Phys. Letters 313 (1970) 405.

8. F. Halzen and G. H. Thomas, Phys. Rev. Dlo $(1974) 344$.

9. I. Ambats, et. al., Phys. Rov. D9 (1974) 1179.

10. R. D. Field, Proceedings of the Summer Studies on High-Energy Physics with Polarized Bcans, Argonnc National Laboratory, ANL/HEP 75-02 (1974).

11. J. M. Potter, et. al., Phys. Rev, Letters 331197411307. 


\section{List of Eigures}

Fig. I Layout of the ZGS experimental areas for polarized beam operation

Fig. 2 Measured polarizations as a function of momentum and quadrupole compensation

Fig. is $\sigma_{\text {TOT Experiment }}$

Fig. 4 Experiment measuring 2 andi 3 spins

Fig. 5 Plot of datic on asymmetry parameter $A$ and $C_{N N}$

Fig. o Plot of the ratio of the differential elastic pp cross section for each spin state to the spin average cross section.

Fig. 7 Plot of the differential elastic proton proton cress sceition for each spin state

Fig. $8 C_{\text {NN }}$ measurements at $6.0 \mathrm{rieV} / \mathrm{c}$

Fig. $9 C_{N N}$ measurements at 3.0 cieV/c

Fig. $10 D_{N N}$ measurements at 3.0 and $6.0 \mathrm{GeV} / \mathrm{c}$

Fig. 11 Scattering matrix formalism

Fig. 12 Small angle polarization in l'-P elastic scattering at $6.0 \mathrm{GeV} / \mathrm{c}$

Fig. 13 Effective Mass Spectrometer

Fig. 14 PP and PXi polarization at 2.0 and $6.0 \mathrm{GeV} / \mathrm{c}$

Fig. 15 Single-flip natural parity exrhange amplitudes from the polarization measurements

Fig. 16 Power law fit to the single-flip amplitudes from the polarization measurements

Fig. 17 Plot of number of events as a function $M_{P_{\pi}}-$ in $P+P \rightarrow P_{\pi}^{-} \Delta^{++}$
at $6.0 \mathrm{Gev} / \mathrm{c}$

Fig. 18 Plot of aurrber of events as a function of $\mathrm{Ni}_{\mathrm{P}_{\pi}}-$ in $\mathrm{Pt} N \rightarrow \mathrm{P}_{\pi}{ }^{-} \mathrm{P}$ at 6. $0 \mathrm{CeV} / \mathrm{c}$

Fig. 19 Plot of nimber nf evenes as a function of $\mathrm{M}_{P_{\pi}}$ in $\mathrm{P}_{\mathrm{f}} \mathrm{P} \rightarrow \mathrm{P}_{\pi}+\mathrm{N}$ at $6.0 \mathrm{Gev} / \mathrm{c}$

Fig. 20 Comparison of the natural and unnatural parity cross scetions for the $\Delta^{++}$andi $K^{0 \div}(890 !$. At $i, 0 \mathrm{GeV} / \mathrm{c}$

Fig. 21 Plot of number of events as is function of $\mathrm{M}_{1 \rightarrow}$

Fig. 22 Generaliaed Wolfenstein Parameters for $\therefore$ polarization 
Fig. 23 Inequality of Polarization and Analyzing power for $\wedge$ as a function of $\mathrm{x}$

Fig. 24 Depolarization Parameter D for $\wedge$ as a function of $x$

Fig. 25 Streamer Chamber Schematic for $\mathrm{P}^{\uparrow}{ }^{4}$ He Interactions

Fig. 26 Schematic of Parity non-conservation experiment 


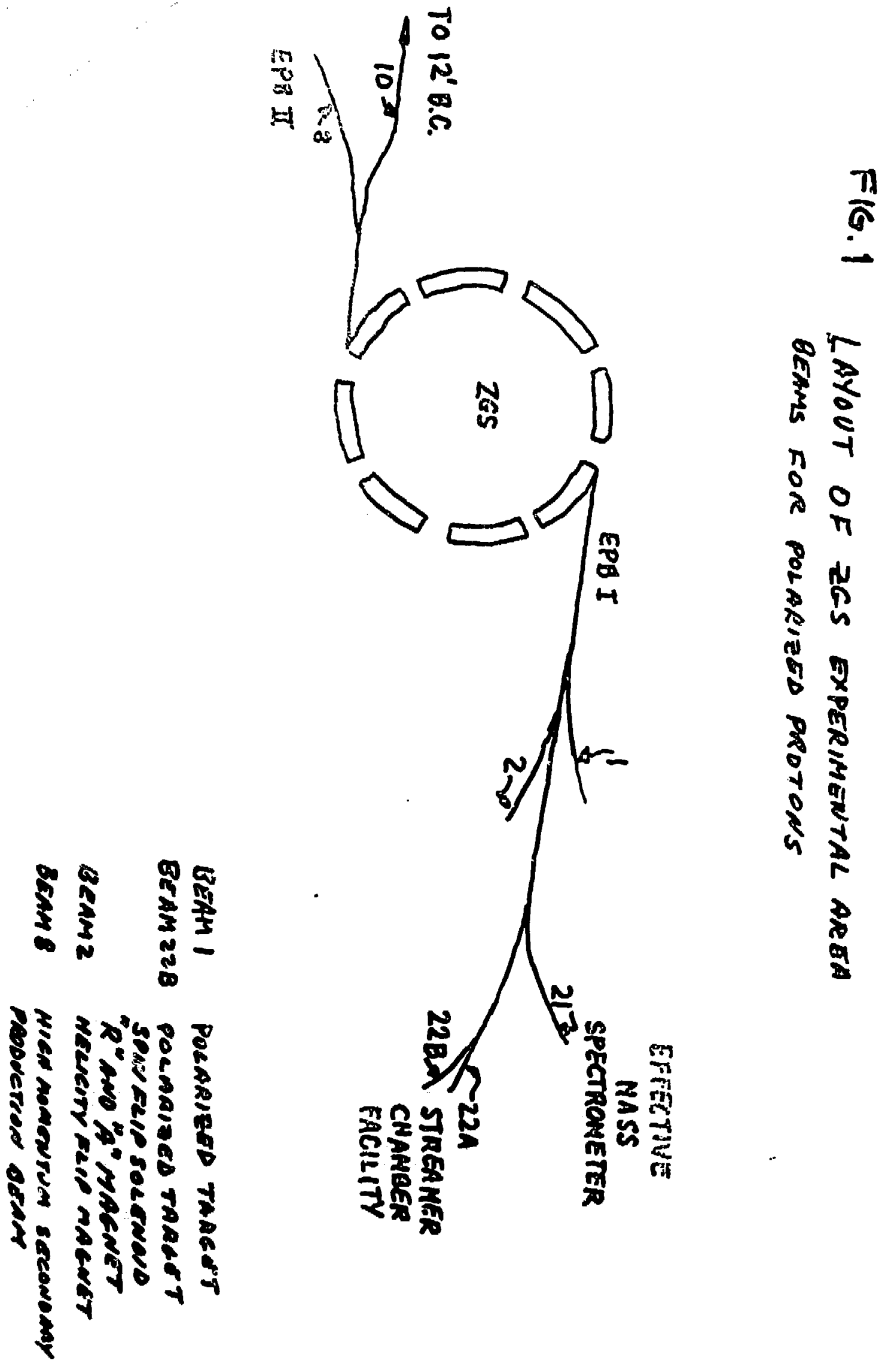




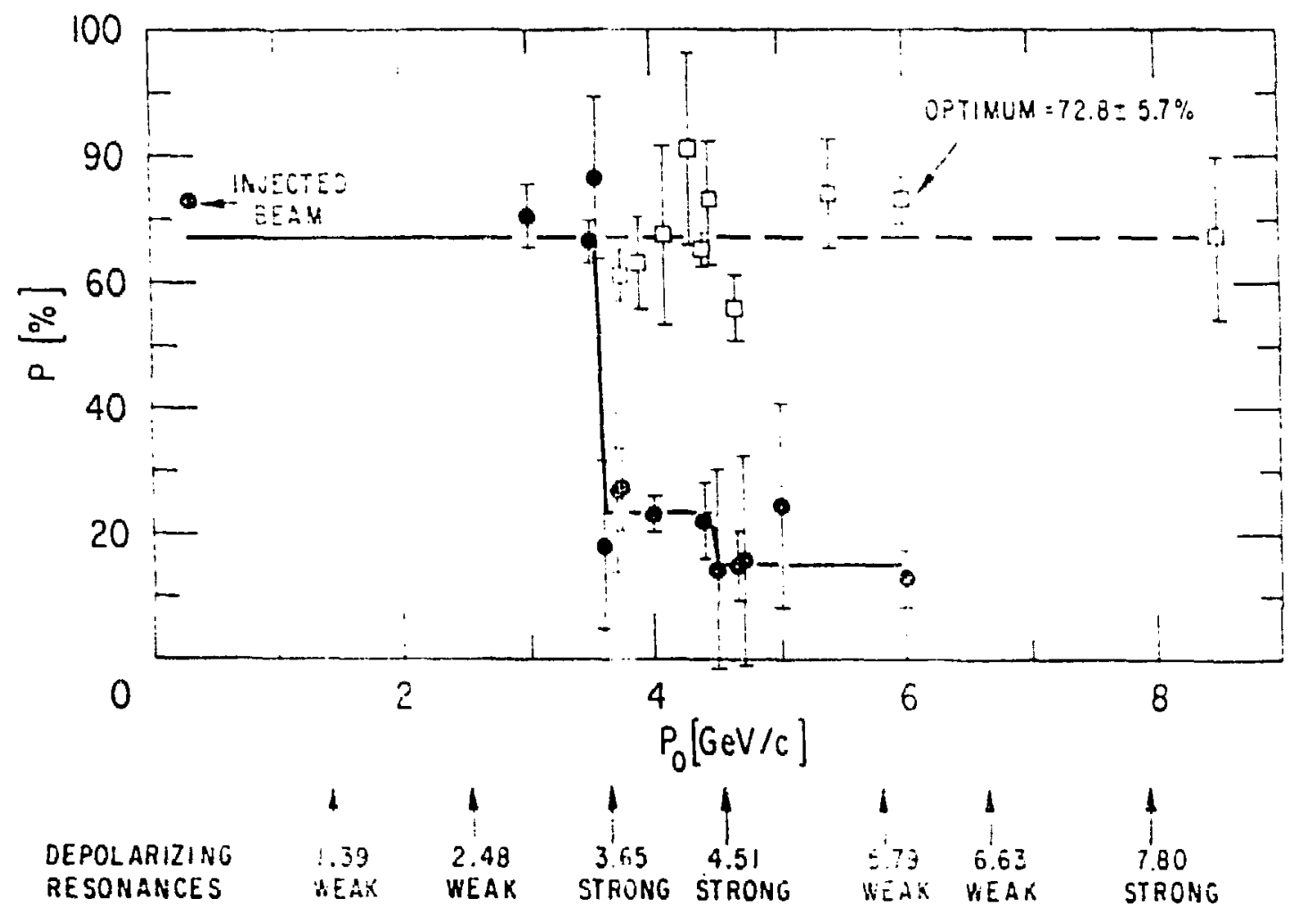

$F 162$ 
NEW MEASUREMIENT OF $\sigma_{T O}$ : IN PROTON-PROTON SCATTERING IN PURE SMIN STATES

W. dE BOSR, R.C. FERNOW, A.D.KRISCH, A. S. MIETTINEN T.A.MULJAA, J.B.ROBERTS, AND K.M.TENWILLIGER

TAS UNIVERSITY OF MICHIGAN

AND

L. G. RATNER

ARGONNE NATIONAL LASGORATORY

TR OND

ST. LOUIS UNIVERSITY

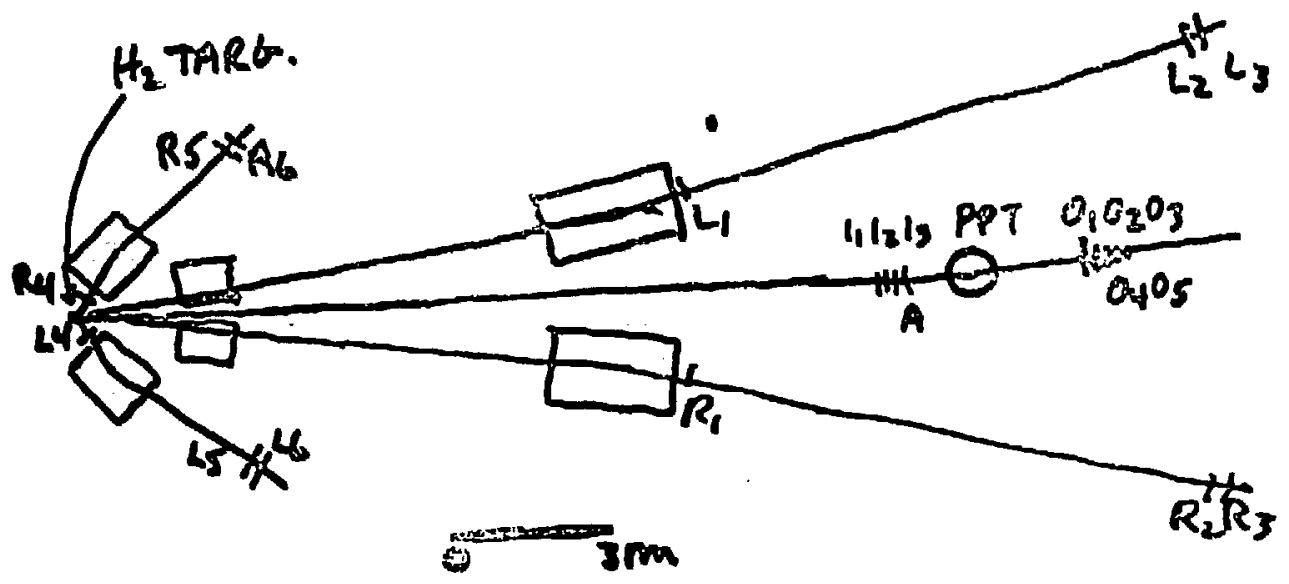

LAYOUT OF EXPERIMENT

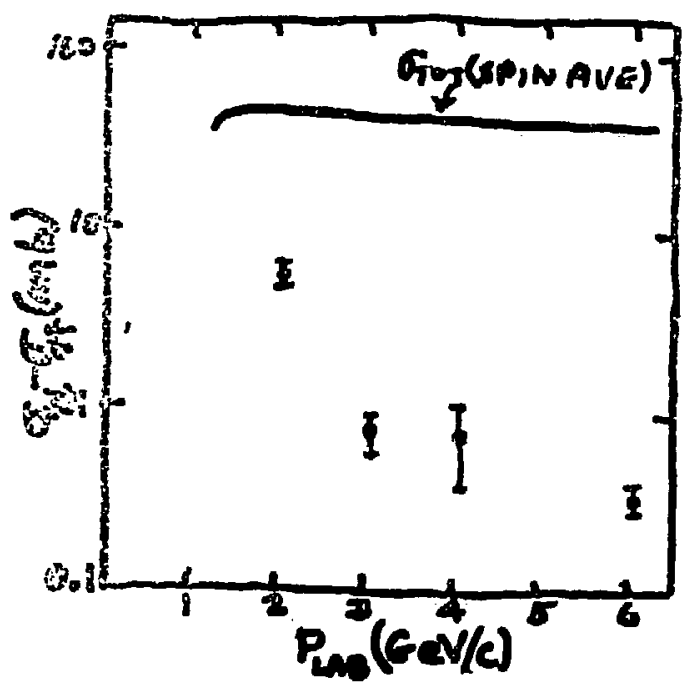

$$
\begin{aligned}
\Delta \sigma_{\text {TOT }} & =\sigma_{\text {TOT }}(N)-\sigma_{\text {TOT }}(A P) \\
& =\frac{-\left\{[I(0 / /)]_{N}-[I(T) / I]\right.}{\langle I(O) / T\rangle N_{O P} t P_{B} P_{T}}
\end{aligned}
$$

DTTET PLOTTED AGAINST IANEIDENS BEAM MONENTUAOA

$F / G, 3$ 
SIMULTANEOU MEASUREMENT OF 2 AND 3 SPH IA PROTON PROTOON ELASTIC SCOTTERING AT 6 GEV/C

R.C.FEONNDW, S.W. GRAY, A.D XRISCH, H.E. METTINEN, J.Q.ROBEI K.M.TERWLLLIG OR

THE UNIVERSITY OF MICHIGAN

W. de BOER

CERN AND THE UNIVEREITY OF MICATIG

F.F.PARKER AND L.G. RATNER ARGONNG NATIONAL LADORATORY

I.R. O'FALLON

ST. LOUIS UNIVERSITY

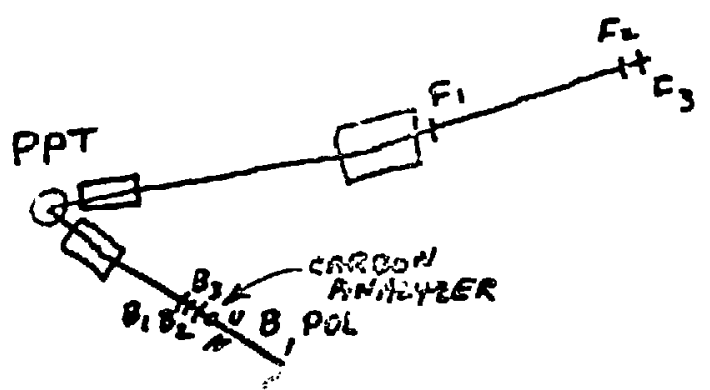

LAYOUT OF 2 ARM SGECTROMETAR ADDED TO PREVIOUS EXPERIASTN

EQUATIONS FOR RELATIVE CROSS SECTIONS

$$
\begin{aligned}
& \frac{d \sigma}{d \Omega}(\mu q)=\langle d \sigma / \Delta \Omega\rangle\left[L+\frac{4\left(N_{s p}-N_{4 b}\right)}{\left(P_{B}+P T\right) \sum N_{i i}}+C_{R N}\right]
\end{aligned}
$$

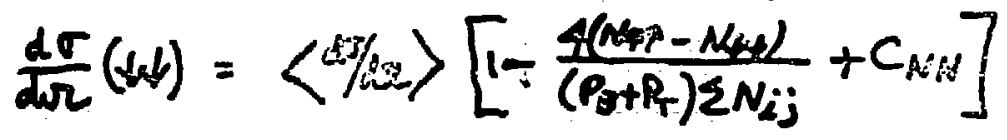

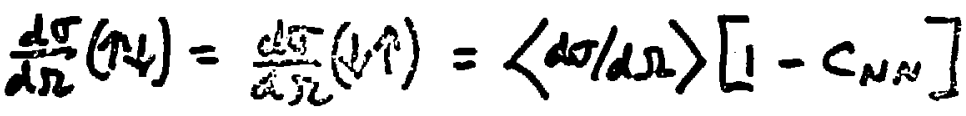

where CNA is Given By

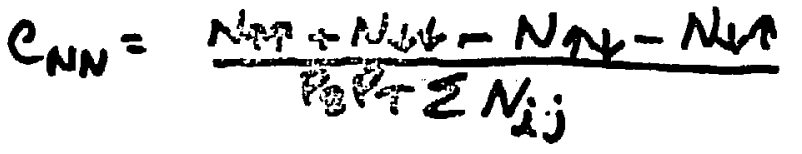

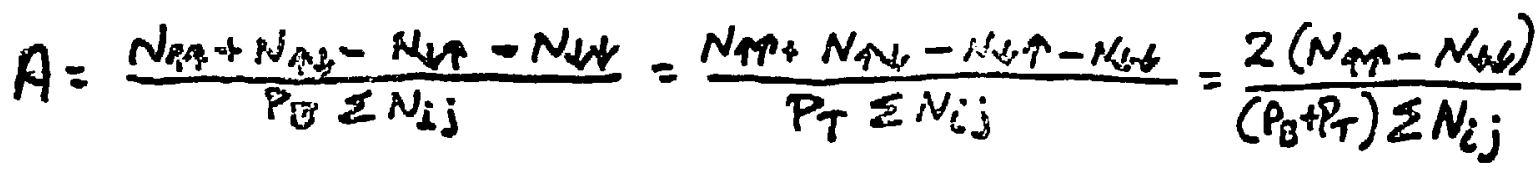

$$
\begin{aligned}
& \text { F/G. } 4
\end{aligned}
$$




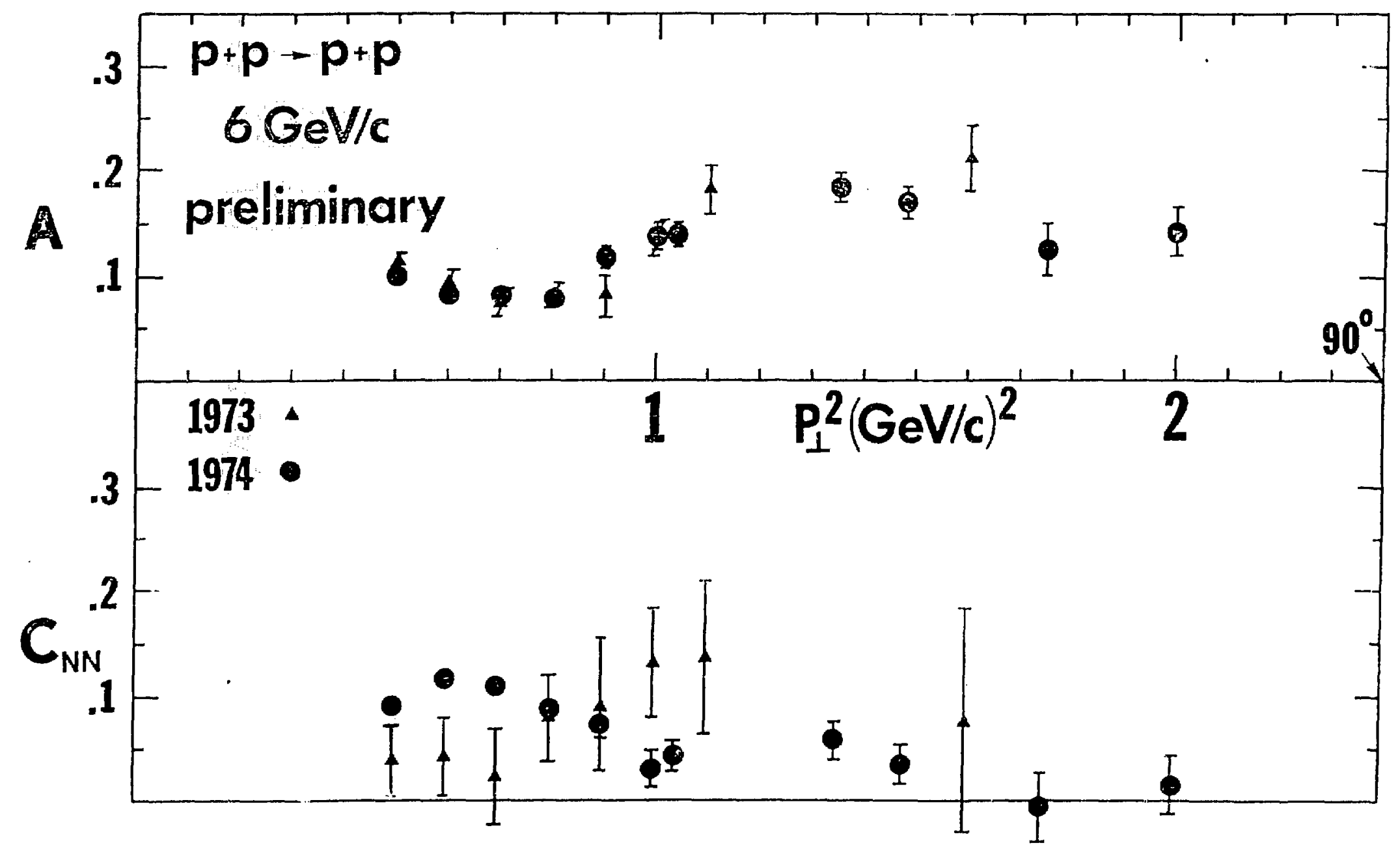

F16.5 


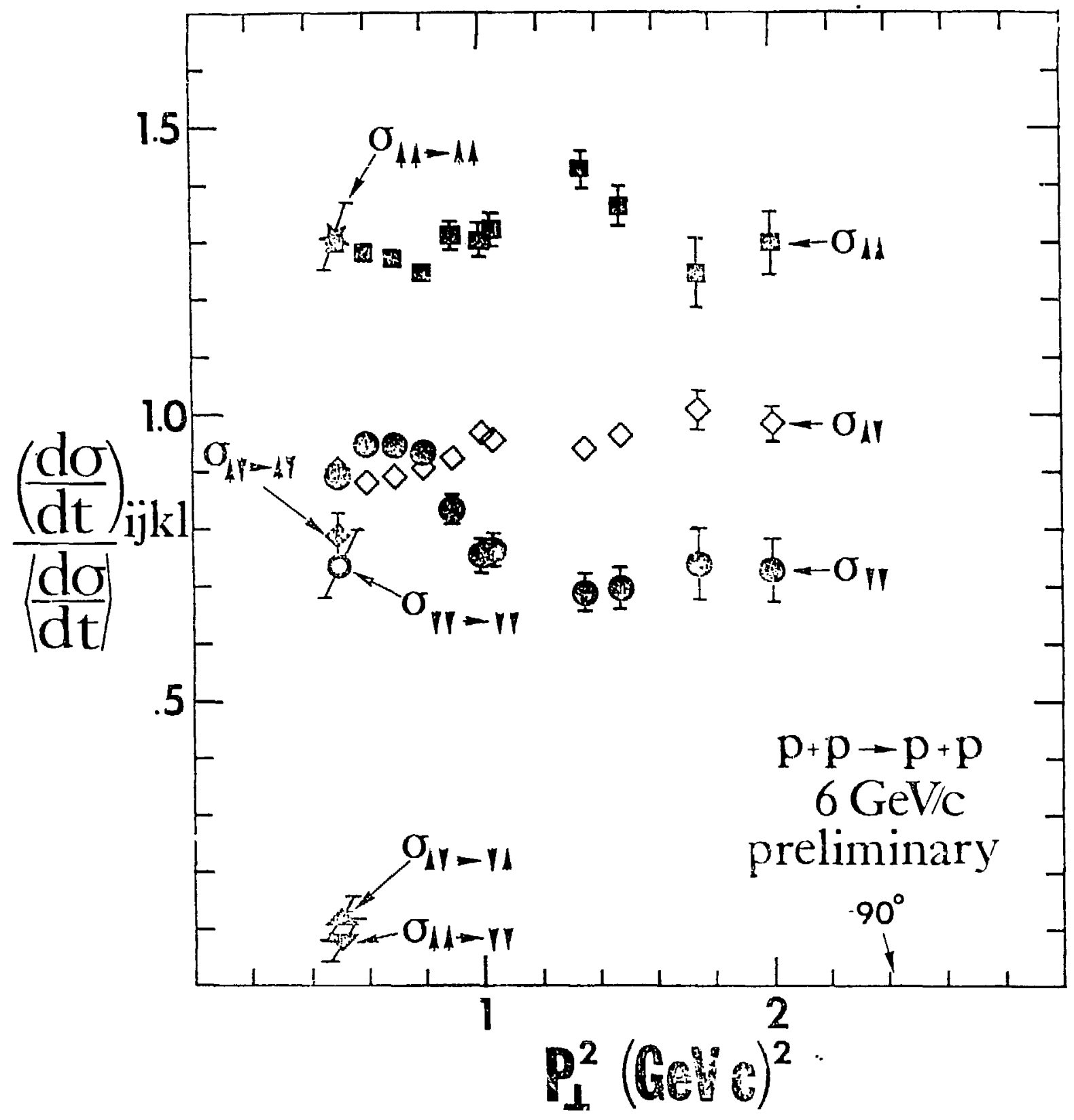

$F / G .6$ 


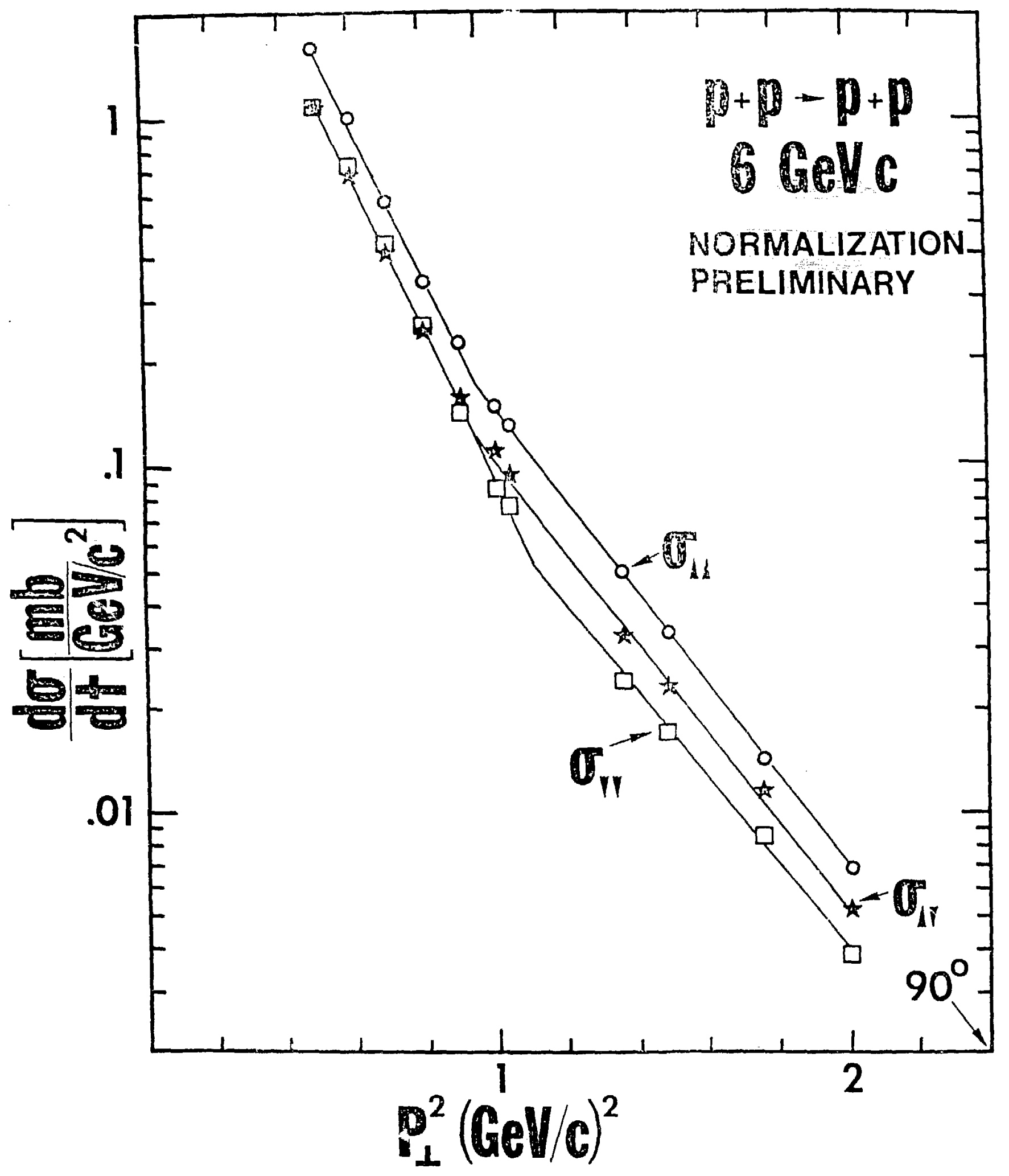

$F \mid G .7$ 
MEASUREMENT OF SPIN-SPI:L CORRELATPON PARAMETER C $C_{N N}$ IN PROTON- DEOTOSON SCATTIERINE AT $6 \mathrm{LOV} / \mathrm{C}$

D. BRIOGES, R. GRESE H.HLL, R. HHLER, P. RYNES K. NIELO, B. SANDLER, ANO A. YOKOSAWA

ARGONNE NATIONAL LABORATORY

AND

R. HICKS, D.MILLER, C. WILSON NORTAWESTERN UNIVERSITY

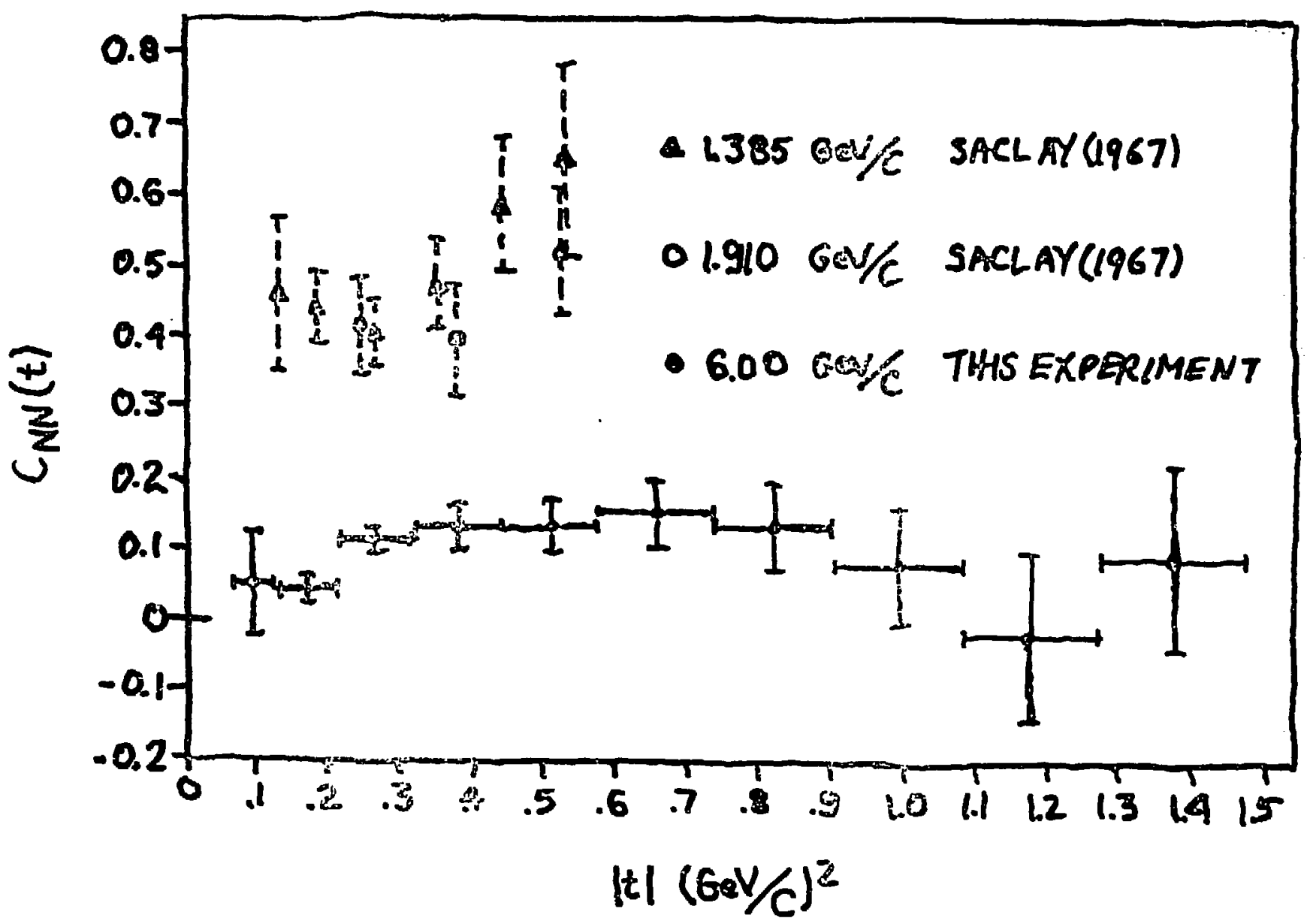

F/G. 8 


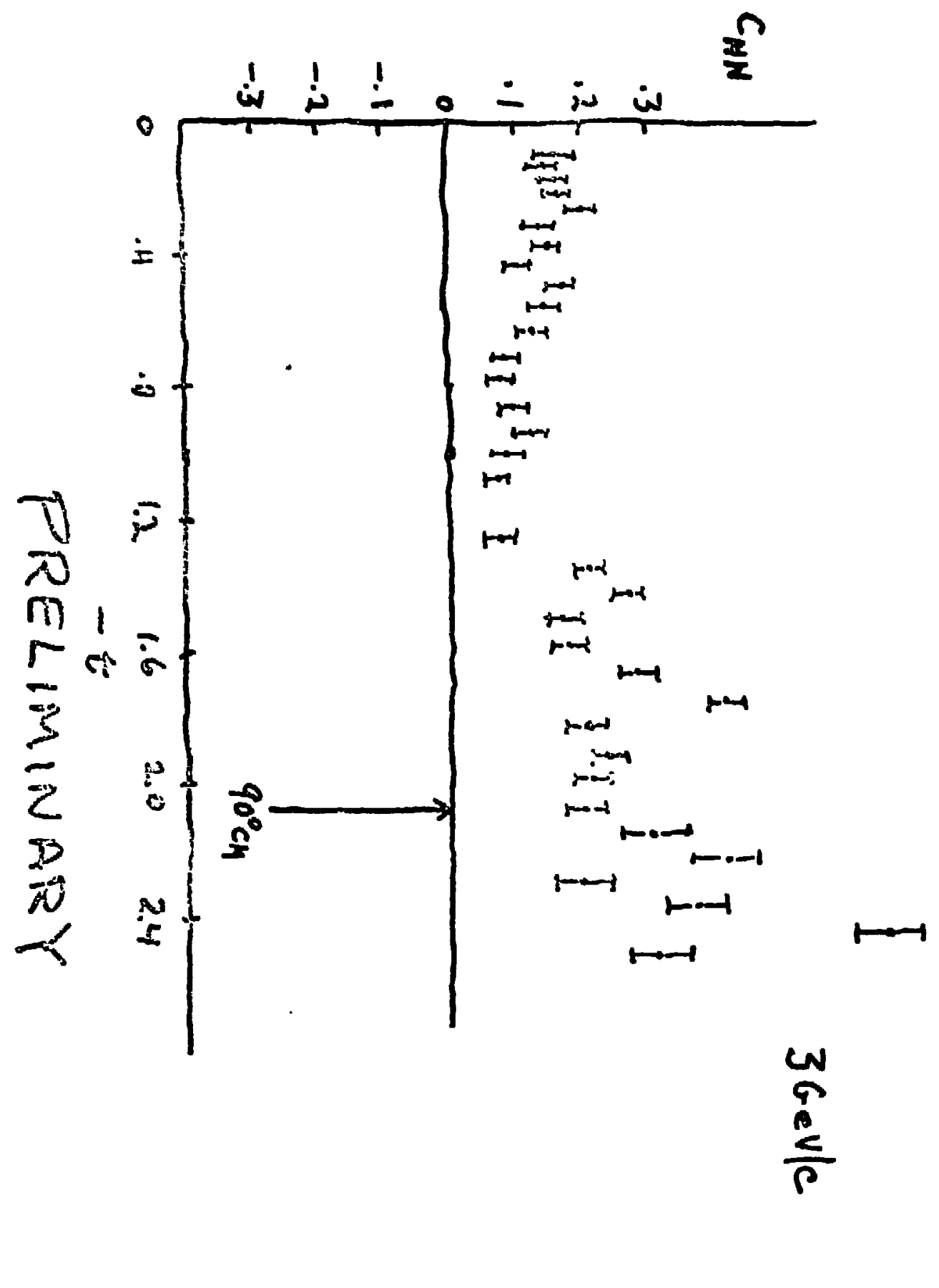


Schumacher $\neq$ Bethe PBSSREX 121 153\%()

$$
\begin{aligned}
M_{T}=A_{T}+B_{T} \sigma_{1 m} \sigma_{2 M} & +C_{T}\left(\sigma_{1 / m}+\sigma_{2, m}\right)+D_{T}\left(\sigma_{1 m}-\sigma_{2 m}\right) \\
& +E_{T} \sigma_{T S} \sigma_{2,8}+F_{T} \sigma_{1 p} \sigma_{2 m}
\end{aligned}
$$

$\sigma_{1}, \sigma_{2}$ Paul matrices for incident and target

nucleons

$\bar{m}, \bar{p}, \bar{q} \quad 3$ mutually perpendicular directions define

by $\bar{n}=\bar{k}_{\text {in }} \times k_{\text {out }}$

$$
\bar{p}=\bar{k}_{\text {in }}+\bar{k}_{\text {out }}
$$

wosisas $\bar{A}$ is the nucleon momentum in the cis system

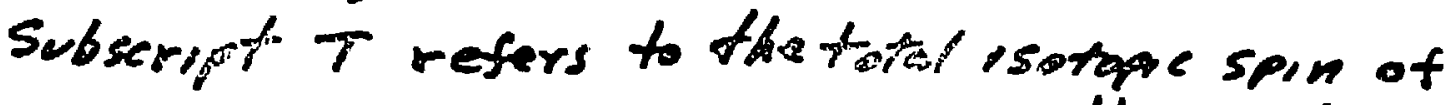
the system

Then

$$
\begin{aligned}
& I_{\theta}=|A|^{2}+|B|^{2}+2|C|^{2}+|E|^{2}+|F|^{2} \\
& I_{\theta} D_{B A O}=|A|^{2}+|B|^{2}+2|C|^{2}-|E|^{2}-|F|^{2} \\
& \frac{1}{2} I_{0} C_{B P}=\operatorname{Re} A B^{*}+|C|^{2}-R_{E} E F^{*} \\
& \frac{1}{2} I_{0} L_{\text {BP A }}=\operatorname{Re} A B^{*}+|C|^{2}+\operatorname{Re} E F^{*} \\
& I_{0} P=2 \operatorname{Re} C^{*}(A+B)
\end{aligned}
$$

FIG. II 
MEASUREMENT SFTHE GPOLARIT, TION PARFAMETER IN SMALL ANGLE PROTON-ENOTON ELACTIC SCATTENINC AT $6 \mathrm{GEV} / \mathrm{C}$

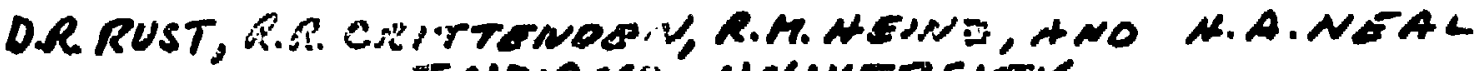
INDIANA UNIVETCSITY

I. AMEATS, O.S. AYRES, R. DIFCOLD, R.J. JOST, S.L. TERAMER W.T. MEVER, A. J. PAWL REK/, C.E.W. WARD

FRCONNE NATENAL LABORAEORY

$$
\begin{aligned}
& \text { A.LESNIK FNA DM SONWART } \\
& \text { SHIO STATE UNINANSIT }
\end{aligned}
$$

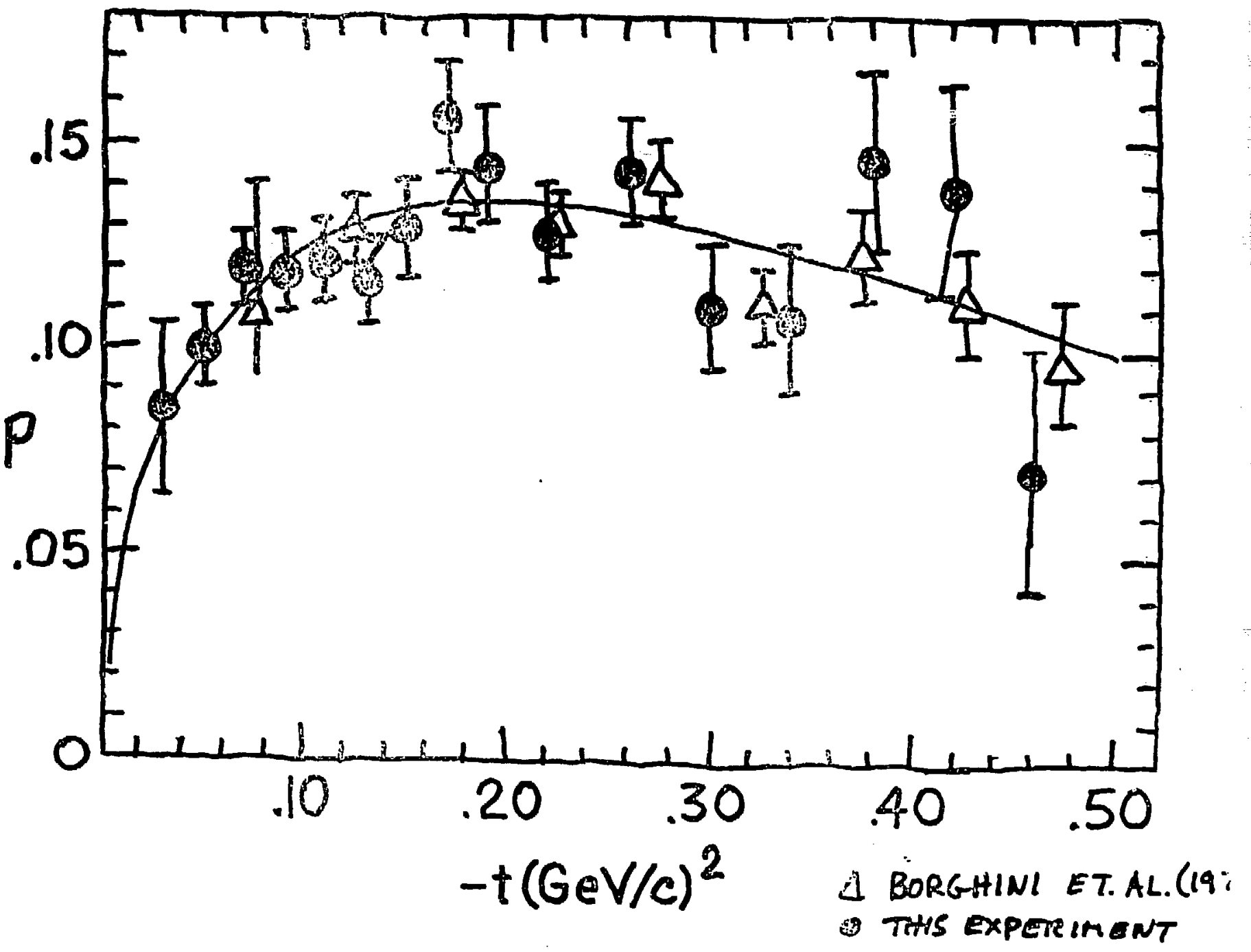

CURVE IS TME EMPIRICAL FORHULA

$P(t)=(2.506 \pm 0.021) \sqrt{-2} \exp [(2.52 \pm 0.18) t]$ 
EFFECTIVE MNS SPECTROIIGTER EXPERMSNNS WITH POLARIZES PEOTON BERM

A.B. WIE:S LUVO, O.S.AYRE S, R.DIECOLO, R.J. JOST S.L.KKRAGSE; AND A.IS PAWLICKI ARGONNE NATIONAL LABORATORY

I. PNA $\rightarrow P N)$

PAP $\rightarrow$ PP FORWARD GLASTIC sorttreRING (10?triggers.

$\sim 500,000$ events each at $3,3,4$, and $b \mathrm{Gov} / \mathrm{c}$

II. $N^{t 5}$ and 4 production $\left(2.5 \times 10^{7}\right.$ triggers)

i 3,200,000 GOOD EVENTS, iNCLUDINE

$$
\begin{aligned}
& P A P \rightarrow P T^{t} N \text { 600,000 at 3Gev/e } \\
& \begin{array}{lll}
600,000 & \because 16 \mathrm{cer} / \mathrm{e} \\
1,300,000 & .1 & 6 \mathrm{cev} / \mathrm{e}
\end{array} \\
& P A N \rightarrow P M T \text { 200,00d I. G GeVfC } \\
& \text { FAp } \rightarrow P \pi^{+} \pi^{-}(P) \quad 500,000 \text { in Goyfe } \\
& \begin{array}{r}
P P_{P} \rightarrow P \pi+\pi-(D) \\
\text { (NN) }
\end{array} \\
& p a p \Rightarrow p \pi \Delta^{++} 100,000 \text { " } 6 \text { Gev/c }
\end{aligned}
$$

III. InClusive $P_{\uparrow} P \rightarrow \wedge x^{++}$at $6 G 0 \mathrm{v} / \mathrm{c}$ $\sim 10,000$ G00D EVENTS
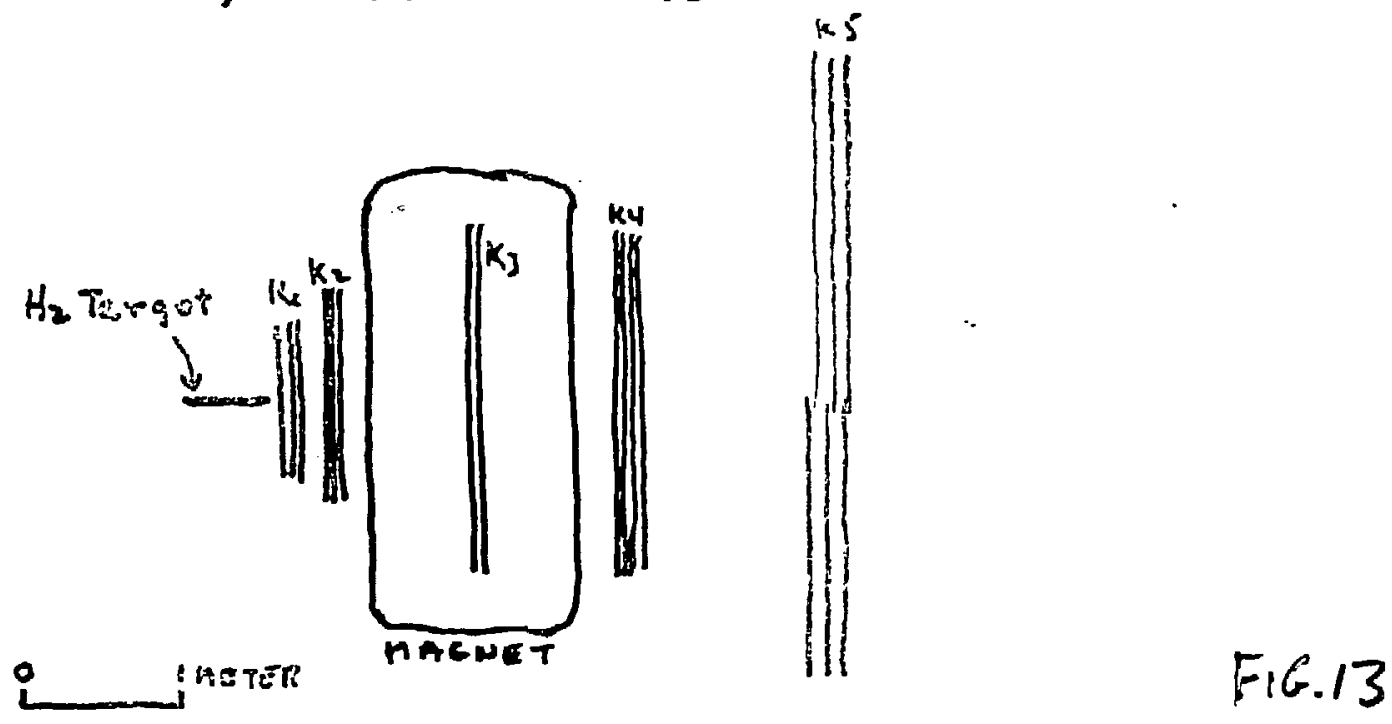

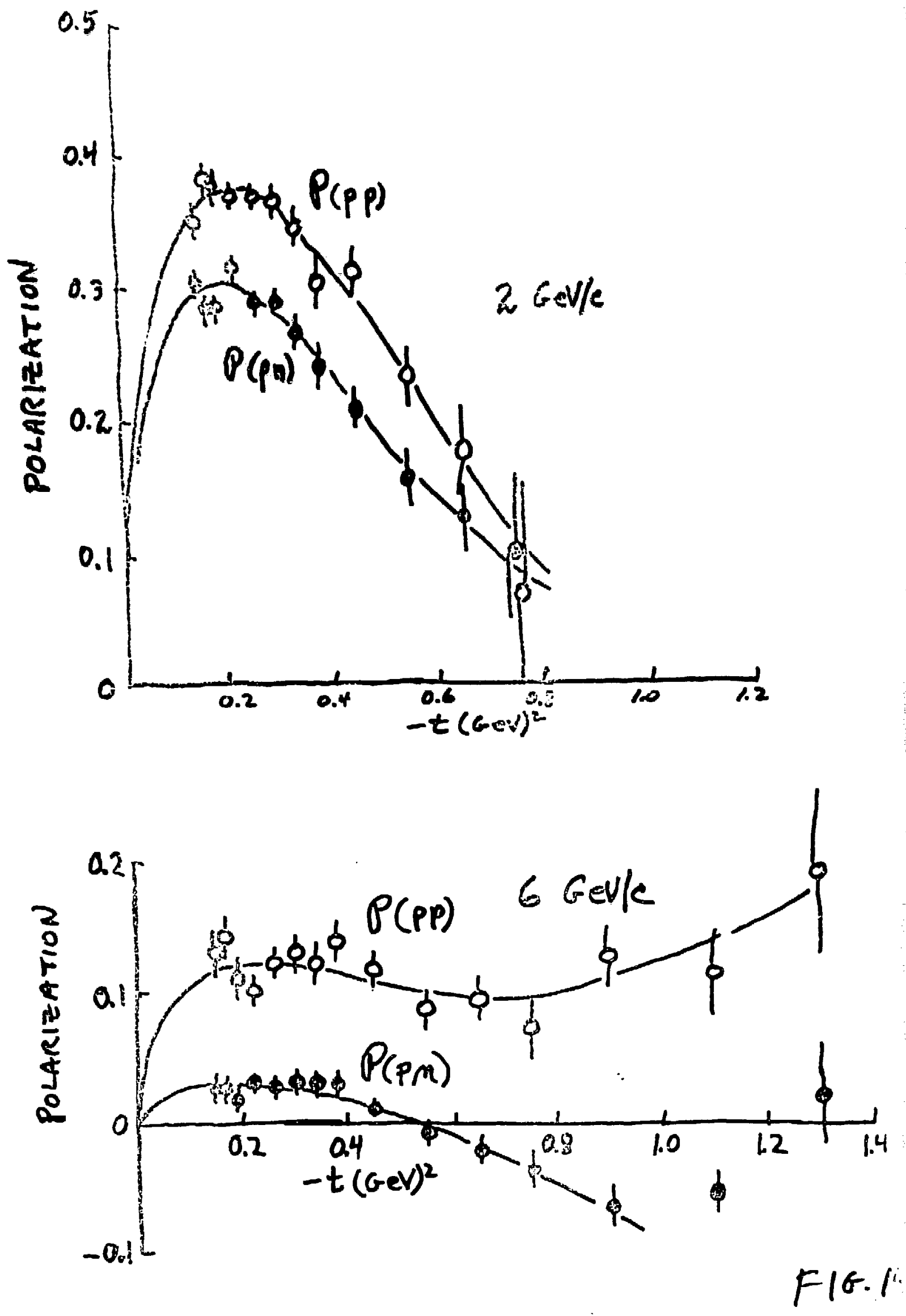
Smate-Fur NatcianteParity Erich Amps.

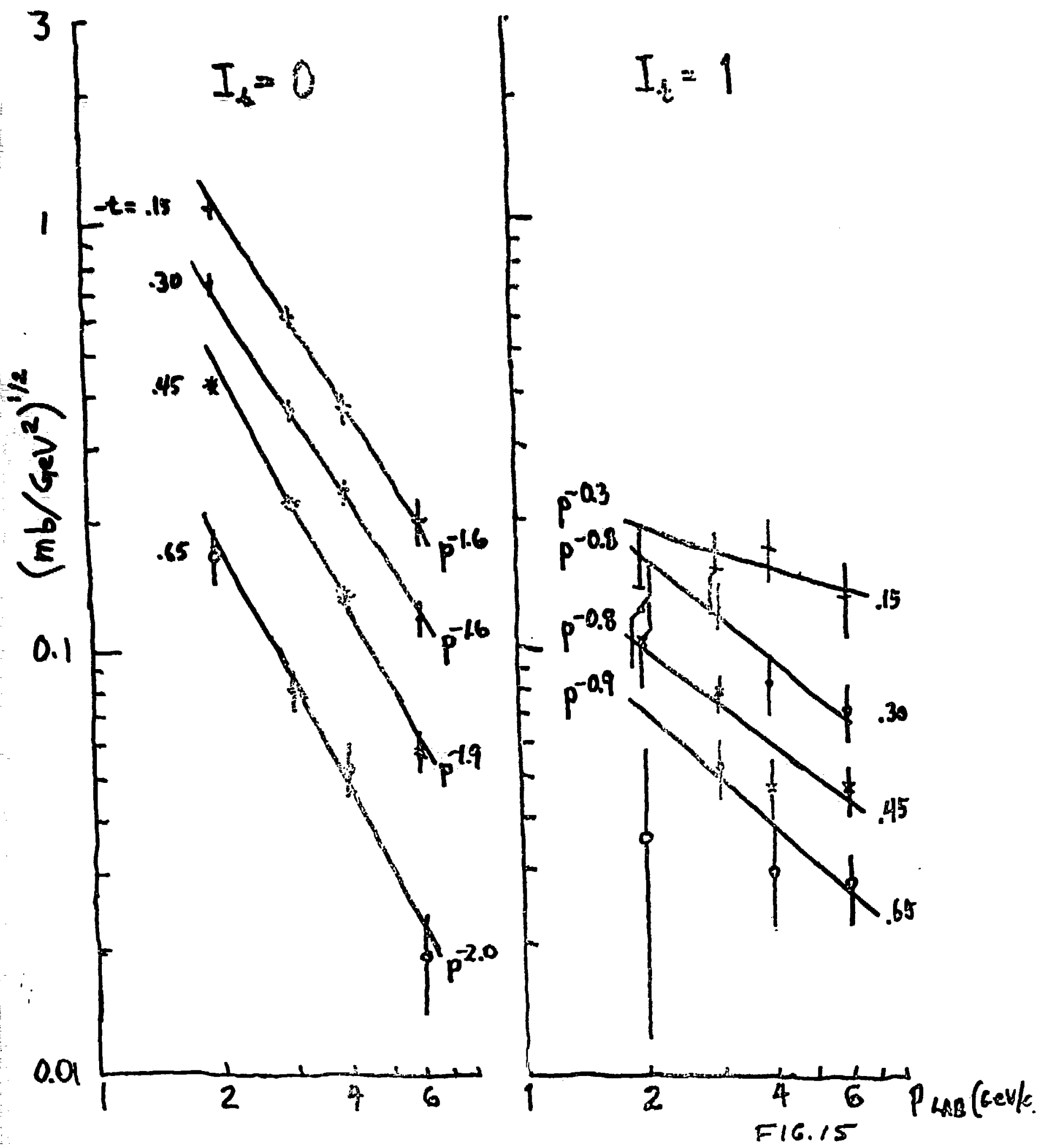




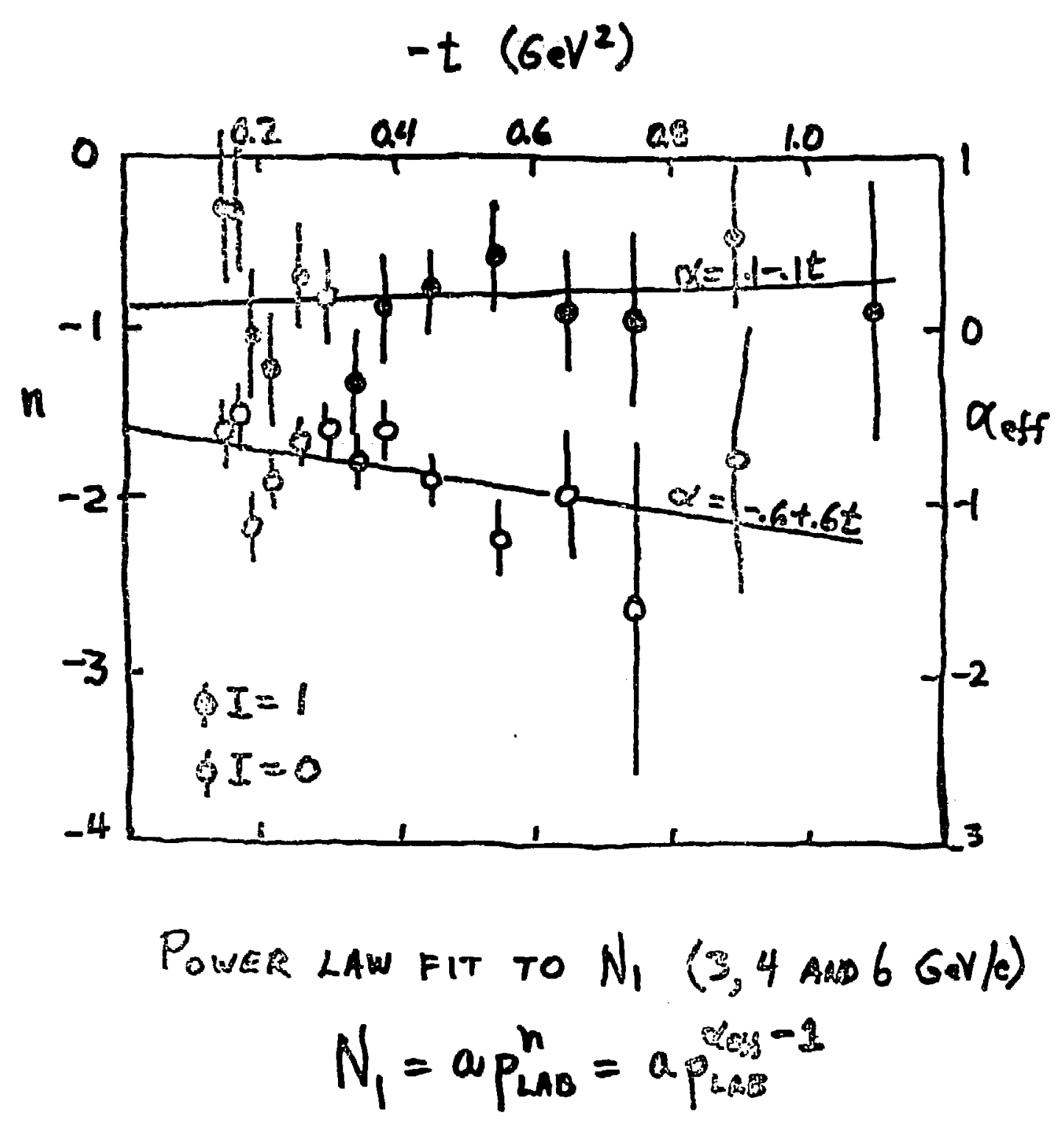

FIG. 16 


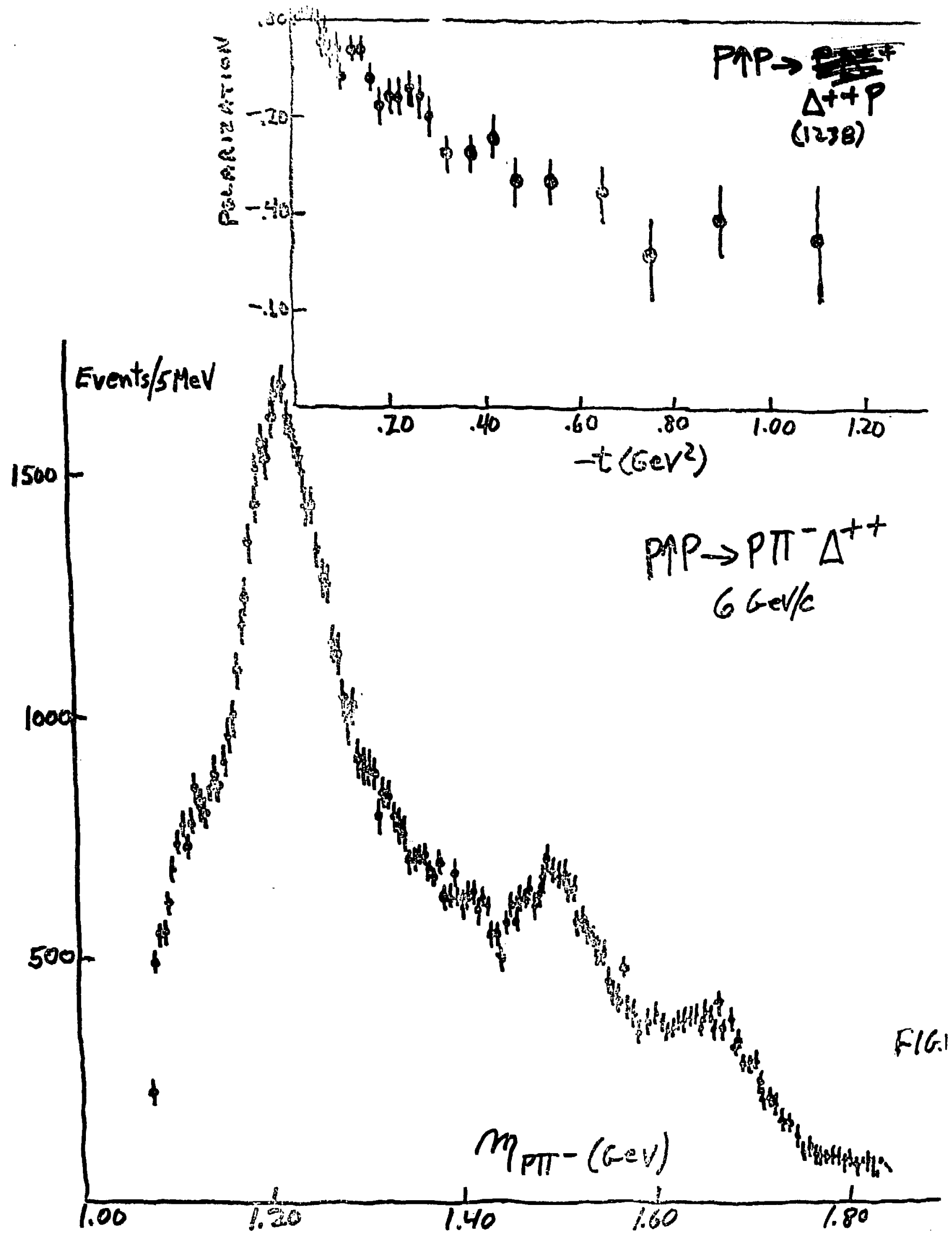




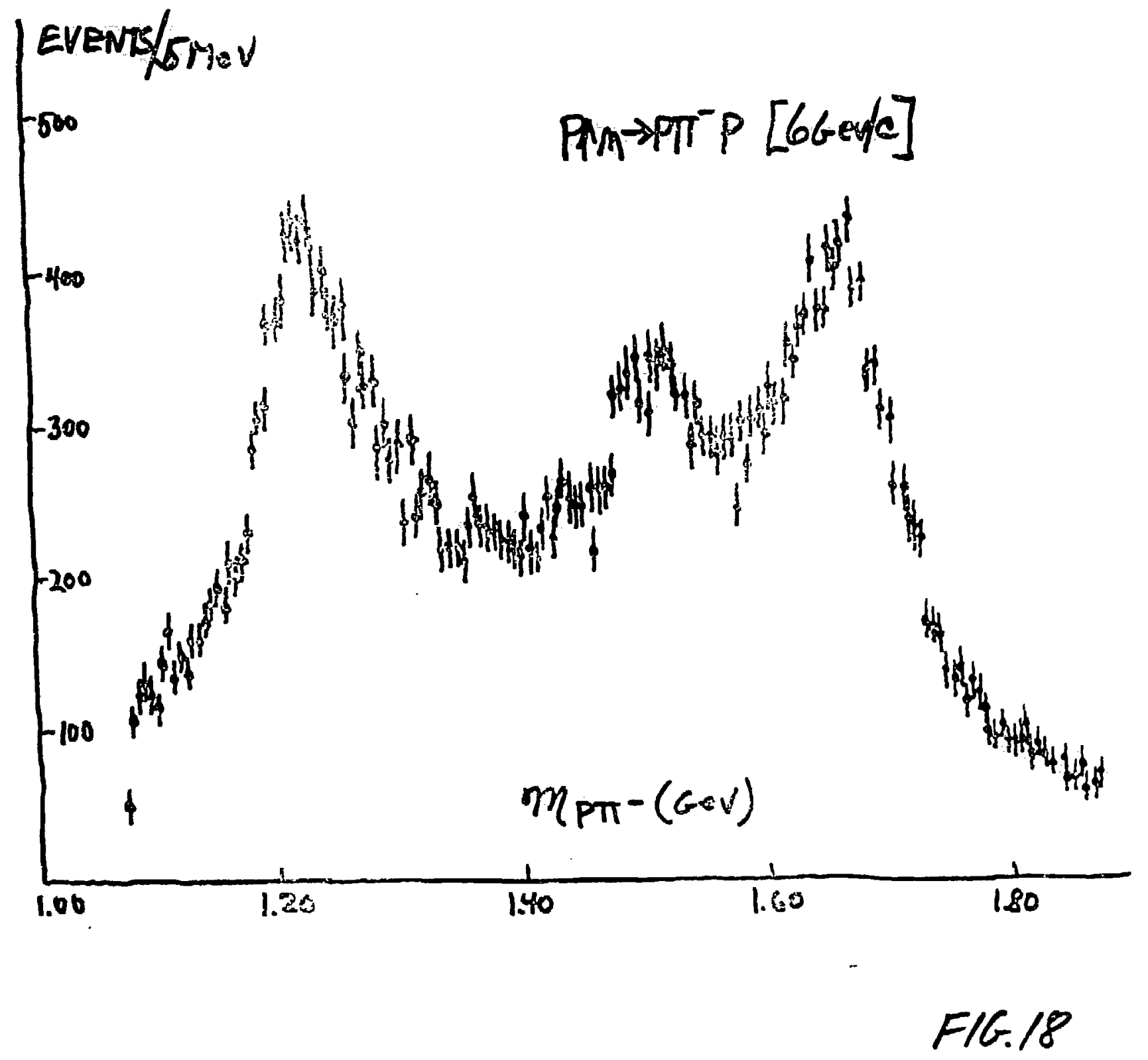




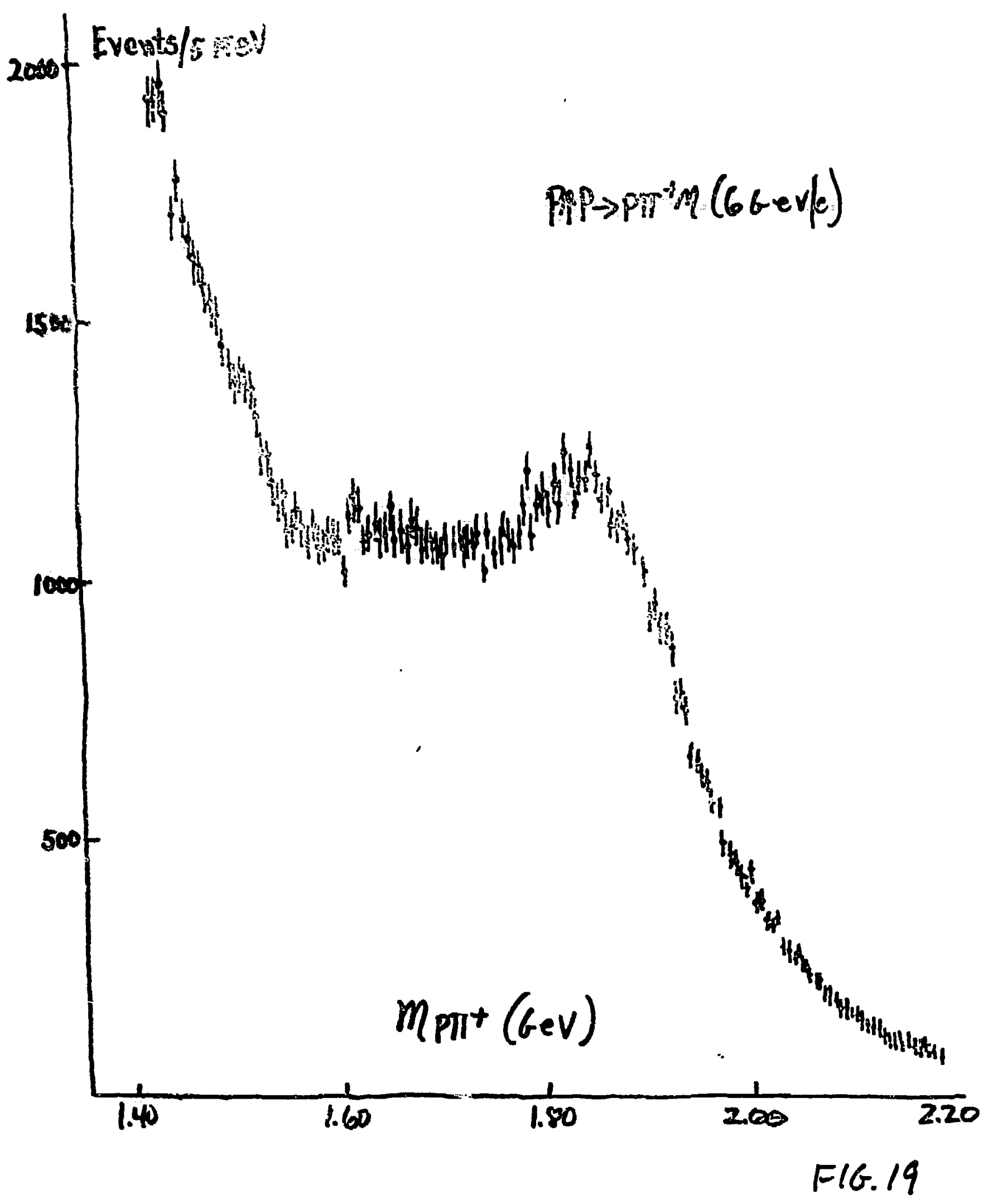




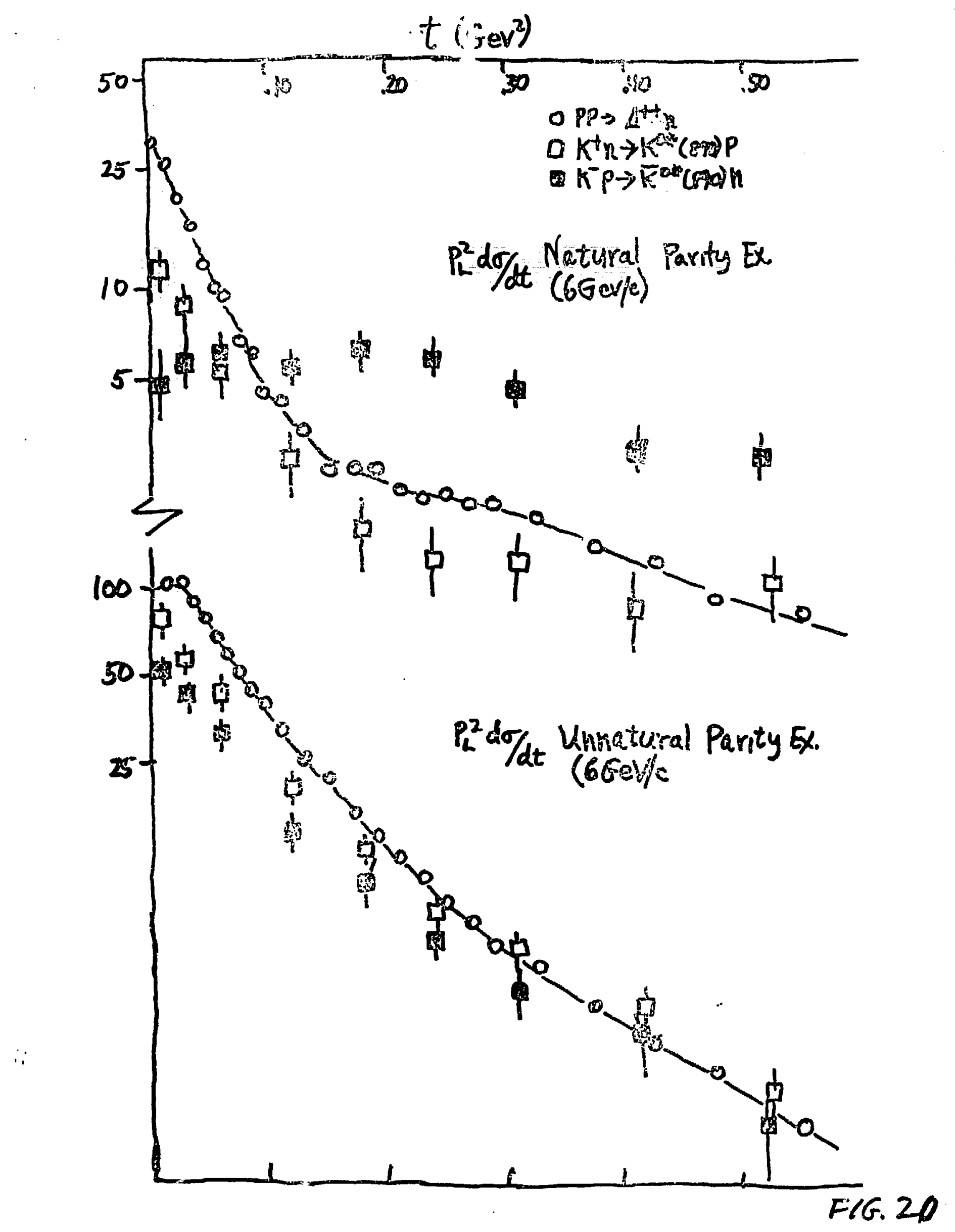



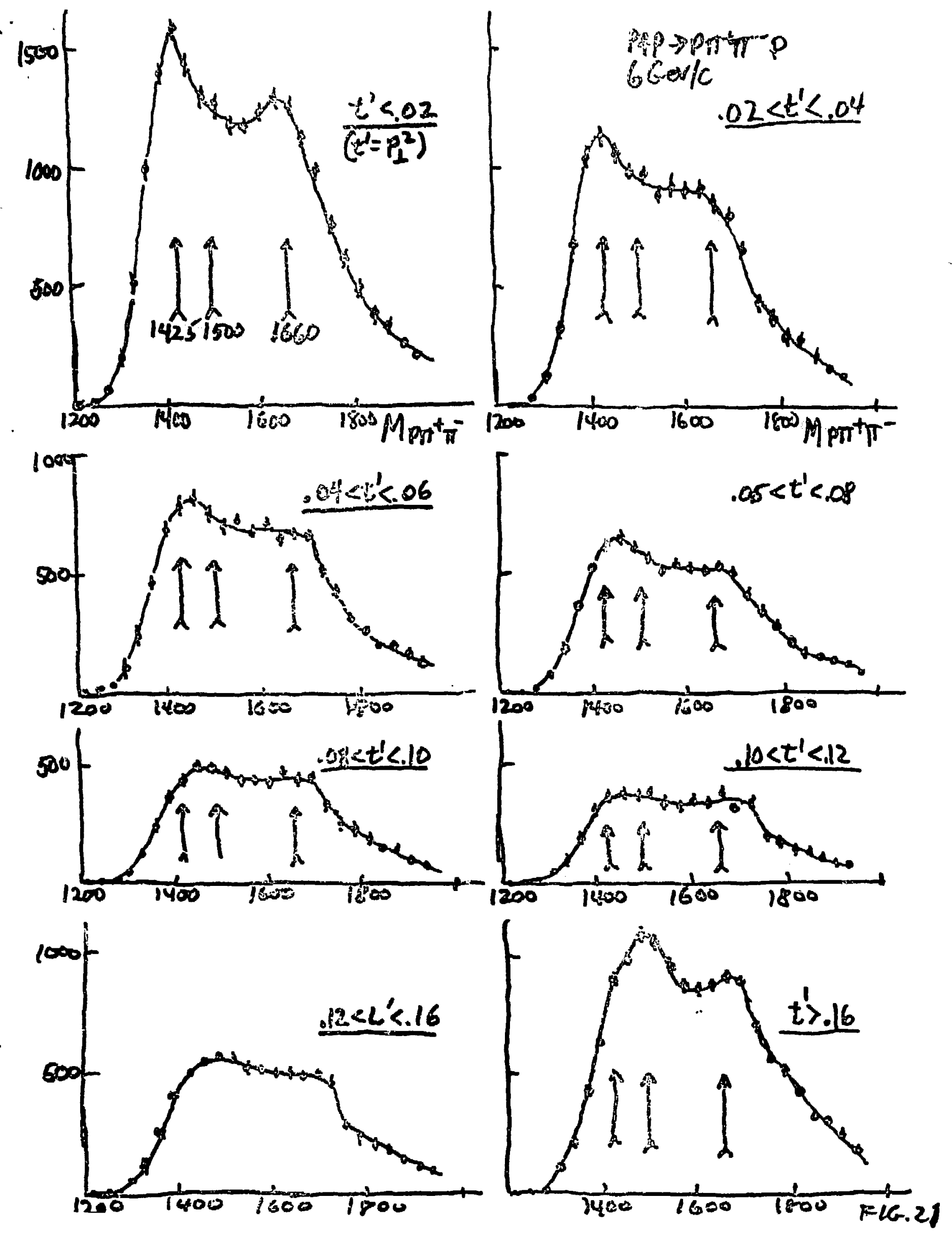
INCLUSIVE PRODOETRON OF $\Lambda^{\circ}$ 'S USINE A POLARIZED PROTO
BEAM

1. AMSSTS E. HAYES, W.T. MEYER, C.E.W. WARD HSGONNE NATIONAT LAOOAATORY

T.M. HNSSSEL, E.C. SWALLOW, R. WINSTON UNIYERSITY OF CQRISACO

A.LESNIK, D.M. SCANGRT Z OATIO STATE UNIUSTSITY

T.A. ROMANOWSKI

AGBONAE NATIONAL LABORATORY AND OHIO STATE UNII

$$
\begin{aligned}
& \sigma=\sigma_{0}\left[1+\left(p-p^{0}\right) \bar{e} \cdot \hat{M}\right] \\
& \sigma \bar{f} \cdot \hat{M}=\nabla_{0}\left[\left(p^{\prime}+p^{\prime}\right)+D \bar{e} \cdot \hat{M}\right]
\end{aligned}
$$

E BEAM POLHRISATTION

f $\Lambda^{\circ}$ POLARISATION

A PRODUETIOAN PLANE UNIT NOREARL

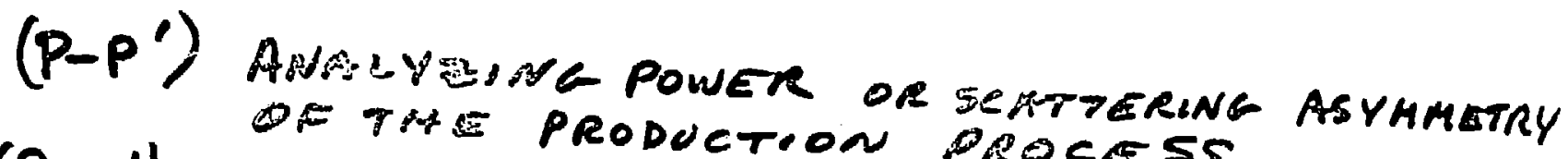
OE THE PRODUCTION DROCESS

$(P+P 1)$ POLASTIEATION DR POLAMISINE POWER 


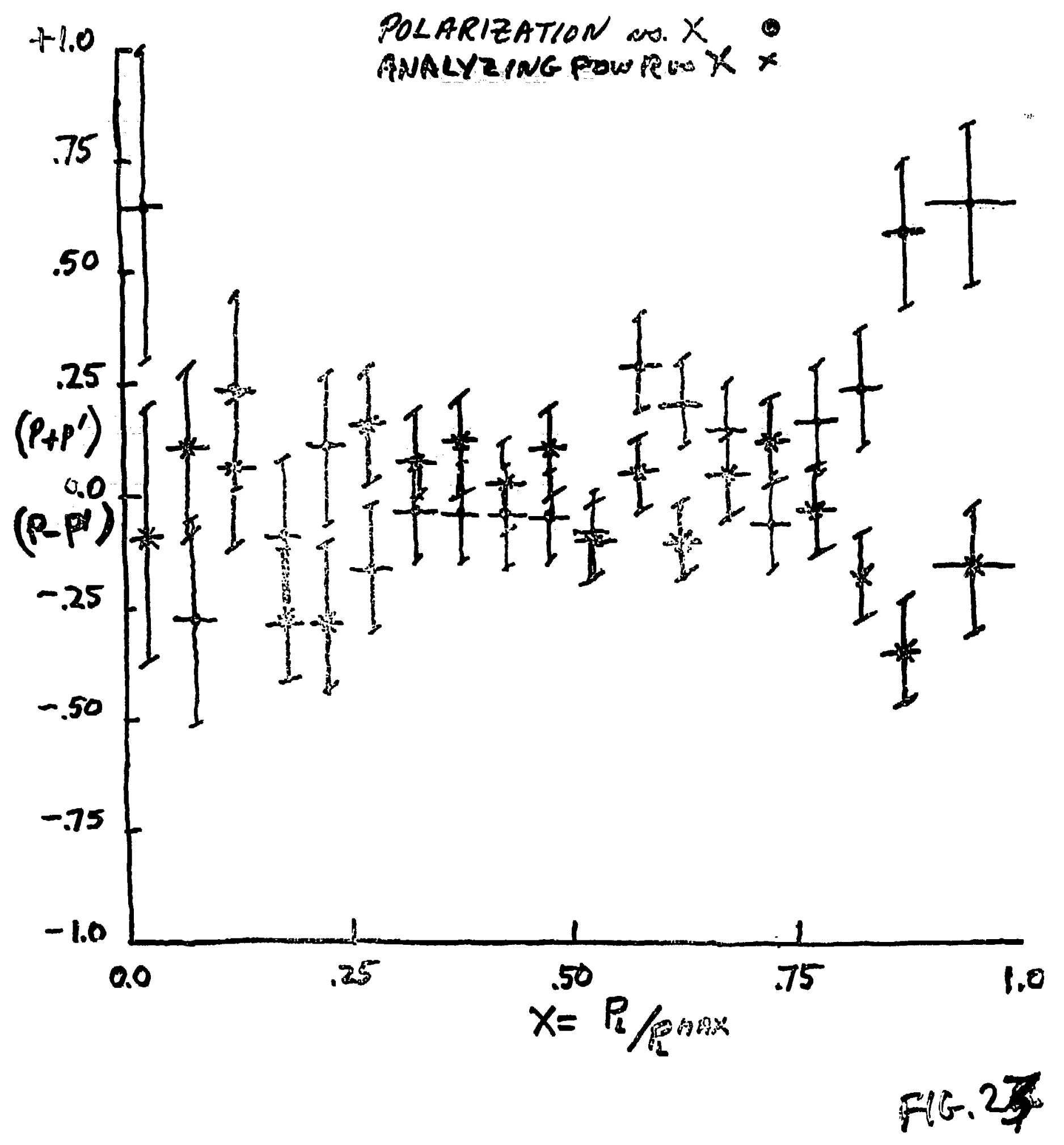




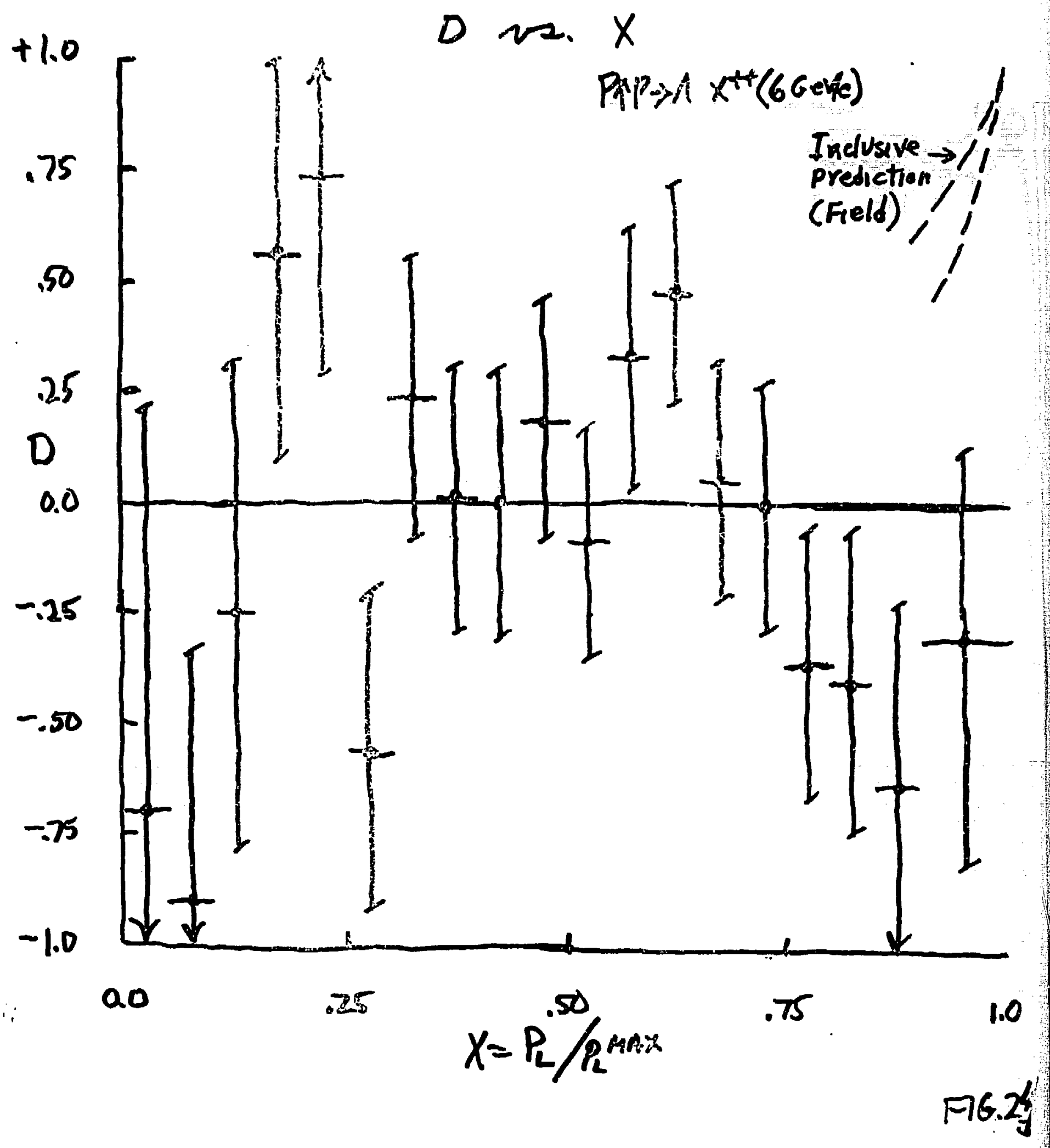


COHERENT PATH INTIRRACTIONS WO STREAHMETR CHAMBETR H.BRAHH, A.FRIDMIN, J-P. LERBER, G. MAURER

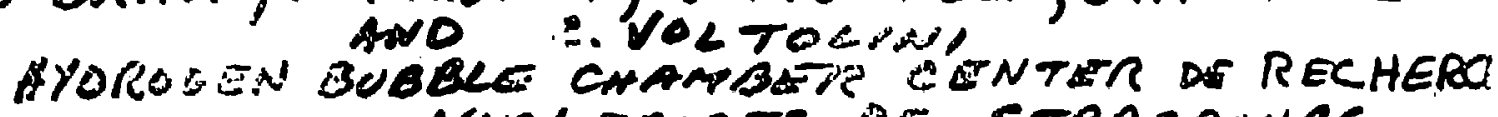
NUCLEAIRES DE STRASBUURG

2. MASSONNET

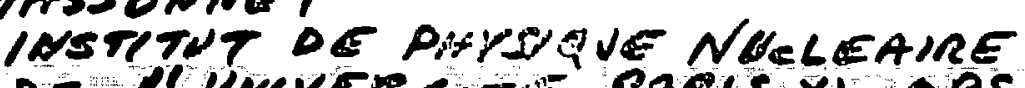

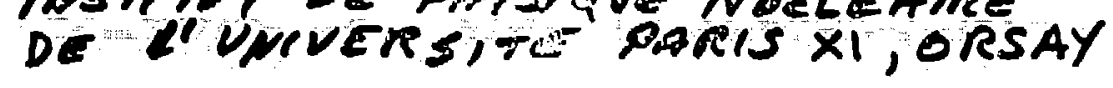

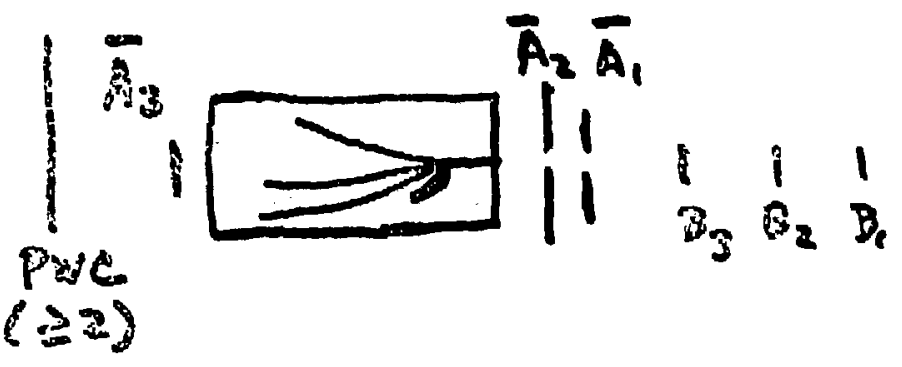

FIG. 25 
LIMIT ON PORTIY NORCONSERVATION IN P-NULLEUS SCATTERANA AT 6 Gev/C $\because$

JO.BOWMAN, C.M. HOJERMAN, C.F. HWANG, R.E. MISCHKE, O.E.NAGLG, AND Y.M. POTTER

UNIVERSITY OF CASIFORNLA, LOS ALAMOS SCIENTIFIC LAMORATORI

AN'D

D.M. ALOE, P.G DEERUNNER, H.FRAUEN FELDER, ANO 1.8. SORGMSON UNIVERSATY OF ILLINOIS, URGANA

ANO.

4.L. ANDERSON AND R. TACAGA UNIVERSATY OF CAICACO

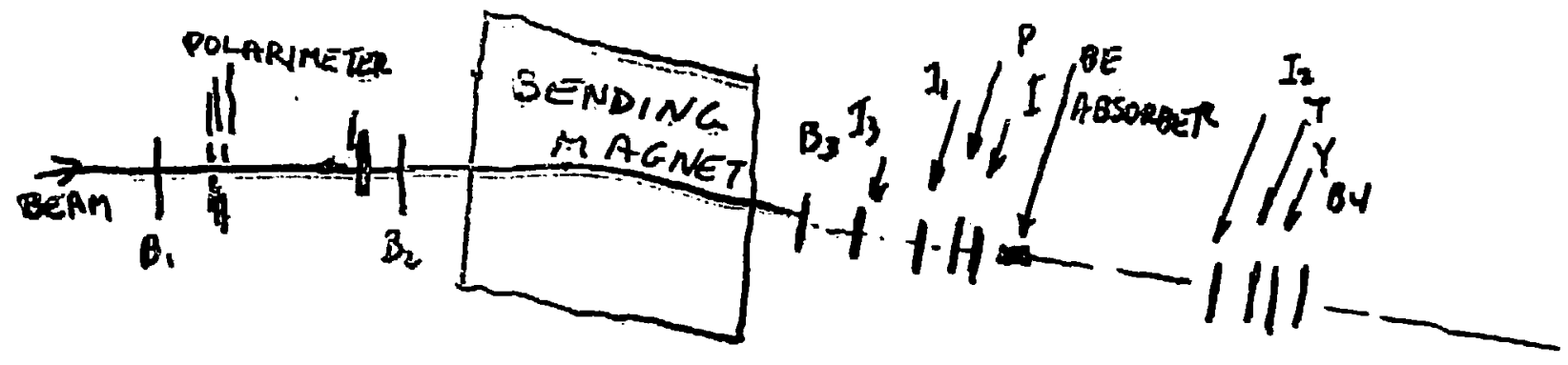

$F(6=2)$ 